Document downloaded from:

http://hdl.handle.net/10251/145857

This paper must be cited as:

Almeida De-Godoy, V.; Zuquette, L.; Gómez-Hernández, JJ. (08-2). Stochastic analysis of three-dimensional hydraulic conductivity upscaling in a heterogeneous tropical soil.

Computers and Geotechnics. 100:174-187. https://doi.org/10.1016/j.compgeo.2018.03.004

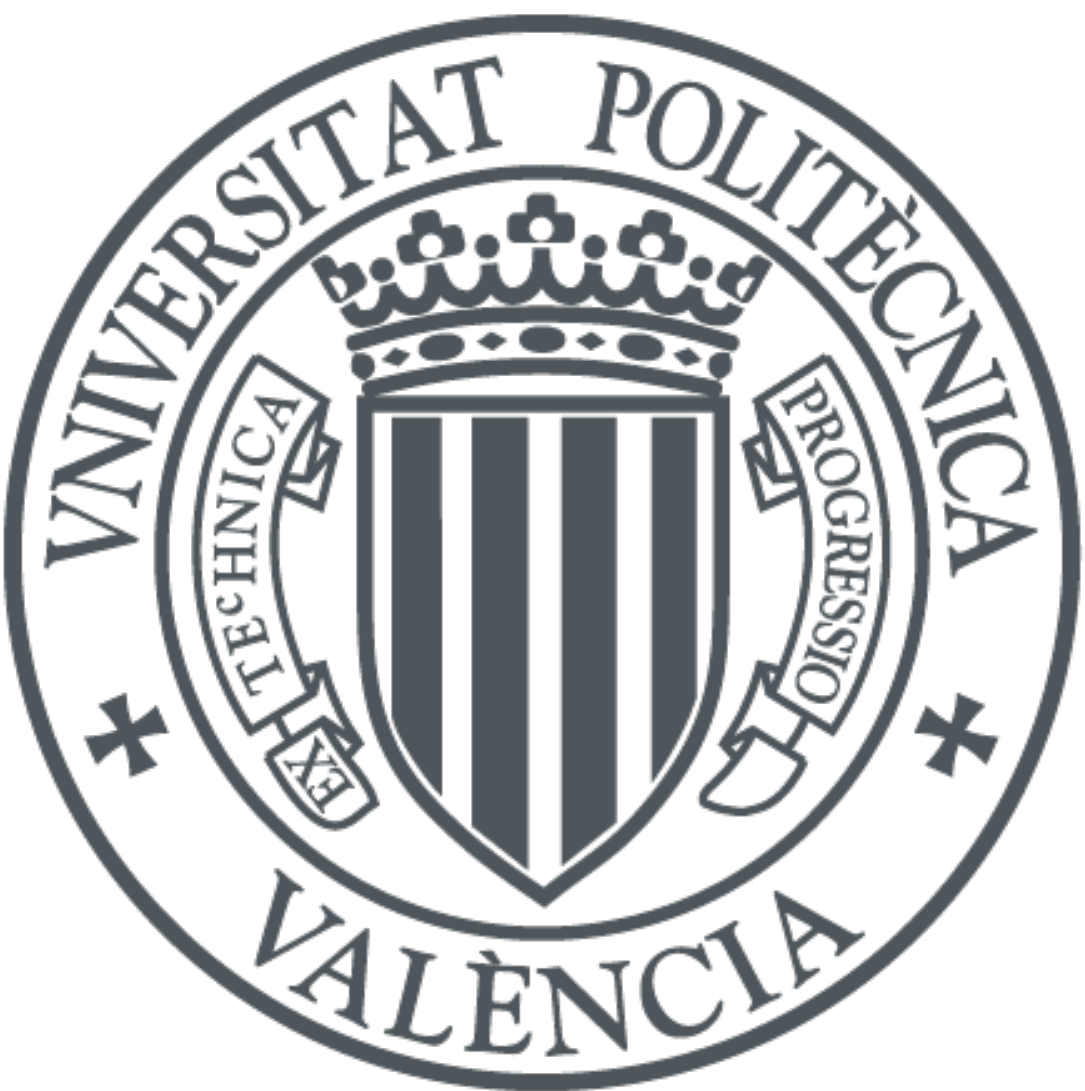

The final publication is available at

https://doi.org/10.1016/j.compgeo.2018.03.004

Copyright Elsevier

Additional Information 


\title{
Stochastic Analysis of Three-Dimensional Hydraulic Conductivity Upscaling in a
}

\section{Heterogeneous Tropical Soil}

Vanessa A. Godoy ${ }^{1,2^{*}}$, Lázaro Valentin Zuquette ${ }^{1}$, J. Jaime Gómez-Hernández ${ }^{2}$

1 Geotechnical Engineering Department, São Carlos School of Engineering, University of São Paulo, Av Trabalhador São Carlense, 400, 13566-590, São Carlos, São Paulo, Brazil

2 Institute for Water and Environmental Engineering, Universitat Politècnica de València, Camino de Vera s/n, 46022, Valencia, Spain

* Corresponding author: vgodoy@sc.usp.br phone number: +55163373-9501

\begin{abstract}
Hydraulic conductivity $(\mathrm{K})$ heterogeneity is seldom considered in geotechnical practice for the impossibility of sampling the entire area of interest and for the difficulty of accounting for scale effects. Stochastic three-dimensional K upscaling can tackle these two problems, and a workflow is described with an application in a tropical soil. The application shows that $\mathrm{K}$ heterogeneity can be incorporated in the daily practice of the geotechnical modeler while discussing the aspects to consider when performing the upscaling so that the upscaled models reproduce the average fluxes at the fine scale.
\end{abstract}

\section{Keywords}

Spatial Variability, Hydraulic Conductivity, Upscaling, Simple Averaging, Laplacian-with-skin

\section{Introduction}

Hydraulic conductivity $(\mathrm{K})$ is one of the most important parameters in many geotechnical studies such as when analyzing slope stability; the dewatering of an underground excavation the design of an earth dam; or the analysis of seepage, flow, and contaminant transport in liners and 
embankments. Most of these problems are approached using numerical simulations, where $\mathrm{K}$ is a key input parameter, the heterogeneity of which plays an important role even in apparently homogeneous soils [1-6]. However, the use of heterogeneous $\mathrm{K}$ fields in numerical modeling in geotechnical engineering is an exception rather than a rule [7-9] because, in general, deterministic approaches that consider $\mathrm{K}$ as a constant value for an entire soil layer are employed $[1,10-12]$. The impossibility of sampling the entire area of interest together with the difficulty of accounting for scale effects [6,13-17] are the two main reasons why heterogeneity is not accounted for in practice. This paper tries to address these two problems and describes how to cope with them.

To face the problem of having scarce information for a complete description of the heterogeneity of K, we use geostatistical techniques such as stochastic simulation or kriging estimation, which permit a coherent assignment of values at locations where measurements were not taken, based on the values observed at measurement locations [18-22].Whether to employ simulation or estimation will depend on the use to be given to the generated maps.

The coherent assignment of values mentioned above does not remove the uncertainty associated with having limited information about the spatial variability of $\mathrm{K}$ in the area of interest; a model of uncertainty is needed, which is built on the framework of stochastic random fields [23]. Hydraulic conductivity will be modeled as a random field, that is, as a set of spatially correlated random variables. At each location in space, $\mathrm{K}$ is modeled as a random variable with a probability density function (pdf) rather than a unique value; the pdf represents the likelihood that $\mathrm{K}$ takes a specific value at that location [20]. It is important to emphasize that $\mathrm{K}$ is not a result of a random process, but the concept of random field is a convenient modeling approach to formalize the problems of estimation and simulation. The random field is fully described by a multivariate pdf, which, in turn, is described by a series of parameters such as the mean, variance, autocorrelation, 
or variogram. In the past years, the number of researchers in geotechnical engineering, who deal with $\mathrm{K}$ heterogeneity in a stochastic way, has increased, but deterministic analysis still prevails $[9,24-28]$.

To face the problem of scale effects, recall that in geotechnical practice, $\mathrm{K}$ is measured at the field or laboratory on a support of around a few centimeters [29,30]. Then, those $\mathrm{K}$ values are used to feed the $\mathrm{K}$ values of a numerical model, where the discretization support is generally orders of magnitude larger than the measurement support [31]. The change of support (from the measurement scale or fine scale to the numerical scale or coarse scale) implies a change in the properties of the random field. The use of some upscaling technique that transfers the information obtained at the fine scale into the coarse scale to be used by the numerical code is necessary to deal with the discrepancy between laboratory and numerical scales [19,32,33]. In other words, the upscaling process seeks a block conductivity $\left(\mathrm{K}_{\mathrm{V}}\right)$ that preserves the total flow crossing the block observed in the block of heterogeneous cell conductivities $\left(\mathrm{K}_{\mathrm{f}}\right)$ for the same hydraulic head gradient. During the transfer between scales, there is a loss of information because the small-scale heterogeneity is not preserved; however, the fluxes occurring at the coarse scale should be the same as those obtained, had the domain being modeled as fully heterogeneous at the small scale. To determine the block conductivity is not a simple task. It should be remembered that the block conductivity, as defined above, is not the arithmetic average of the cell values within the block, which is a common geotechnical practice to upscale $\mathrm{K}$ when only a few measurements are available [34].

Many authors had worked to improve the upscaling methods, which range from simple averaging to the Laplacian-with-skin method with uniform and nonuniform coarsening. They have achieved very good results, showing some advantages, limitations, and the evolution of the $\mathrm{K}$ upscaling techniques in a variety of problems [18,32-48]. In addition, some relevant works associated with 
geotechnical engineering showed that coupled approaches should be used in the upscaling of soil properties to properly model some of the behaviors of heterogeneous soils, e.g., consolidation [9,49]. There are also complete reviews on saturated $\mathrm{K}$ upscaling methods [31,50,51], and the reader is encouraged to read these papers. The nomenclature used hereafter to refer to the different upscaling approaches is taken from the first reference [31]. Some conclusions found in the literature are that the $\mathrm{K}$ upscaling is site specific and depends on the boundaries conditions, block size and shape, statistical isotropy, block size relative to the correlation length, dimensionality of the problem, and complexity of the studied environment. Once the problem of upscaling is resolved, one should not forget that cell values (from which the block conductivities are computed) are never exhaustively known; therefore, it is necessary to quantify the uncertainty associated with the upscaled values using a stochastic approach [48].

In this paper, we would like to focus on two upscaling methods, a simple averaging method, specifically the empirical power average [52] or p-norm, and the Laplacian-with-skin method [48]. The former method has advantages such as usefulness, simplicity, and widespread use [38,39,43,52-54], while the latter method has advantages such as robustness and very good reproduction of the fine scale flows at the coarse scale $[18,19,32,48]$.

It is important to stress that almost all the background information provided here was developed in petroleum engineering and hydrogeology. Very few studies associated with $\mathrm{K}$ upscaling have been found in the geotechnical engineering literature $[9,47,49,55]$; to the best of our knowledge, the more sophisticated Laplacian-based upscaling methods have not yet been applied in geotechnical engineering. Tropical soils have a very specific behavior and are a source of many geotechnical problems; this paper presents, for the first time, an application of $\mathrm{K}$ upscaling to this type of soil. 
The power-average method was used to upscale $\mathrm{K}$ for a unique block size for a 3D anisotropic real aquifer [32] and for a bi-dimensional hypothetical aquifer [38]. Power average was also used to determine $K_{V}$ for a range of block shapes for synthetic cases [39]. In the last two works, the exponent of the power average was determined based on numerical experiments. The simpleLaplacian technique was used in a bi-dimensional conceptual model based on data from a real site in the context of nuclear waste disposal [20]. K upscaling by the Laplacian-with-skin method was applied in a realization of a three-dimensional synthetic $\mathrm{K}$ field [18]. This technique was also used to determine $\mathrm{K}_{V}$ for three block sizes in a bidimensional numerical example, after solving the flow equation by a finite-difference numerical model with the approximation of the interblock conductivity [18].

To summarize, this paper has three objectives: (i) an analysis of stochastic 3D hydraulic conductivity upscaling using the Laplacian-with-skin method [48] for a variety of block sizes using real $\mathrm{K}$ measurements obtained in a tropical soil in Brazil; (ii) to demonstrate the errors that can be introduced by using a deterministic upscaling using harmonic, arithmetic, and geometric averages of the measured $\mathrm{K}$ without accounting for the spatial correlation; and (iii) to show how and when the p-norm averaging can be used (for the tropical soil studied) as an alternative to the more complex and time-consuming Laplacian-with-skin method, with the aim of providing a practical and fast solution for the daily practice of the geotechnical modeler. As a by-product of this third objective, the dependence of the exponent of the p-norm as a function of the block size is analyzed.

\section{Hydraulic Conductivity Upscaling Methods}

The main objective of upscaling is to obtain a block $\mathrm{K}_{V}$ value that reproduces the groundwater flow at the coarse scale as if it had been computed at the fine scale. The aim is to replace a 
finely discretized heterogeneous spatial distribution of conductivities $K_{f}$, with a set of block values $\mathrm{K}_{\mathrm{V}}$, so that the flow response of the set of coarse block values matches the response at the fine scale.

Upscaling methods can be classified as local and nonlocal [31]. Simple averaging techniques are local methods and assume that $\mathrm{K}_{\mathrm{V}}$ depends only on the $\mathrm{K}_{\mathrm{f}}$ values within the block $[35,37,56]$. For a perfectly layered soil, it can be shown that $\mathrm{K}_{\mathrm{V}}$ is equal to the harmonic mean $\left(\mathrm{K}_{\mathrm{h}}\right)$ of the cell conductivities inside the block when the flow is perpendicular to the layers, and to the arithmetic mean $\left(\mathrm{K}_{\mathrm{a}}\right)$ when the flow is parallel to them [56]. It can also be shown that for 2D flow in an isotropically heterogeneous field with lognormally distributed conductivities, $\mathrm{K}_{\mathrm{V}}$ is equal to the geometric mean $\left(\mathrm{K}_{\mathrm{g}}\right)$ of the cell conductivities [35,36]. For 3D-flow, there is no closed form for the best average process because it will depend on the statistical isotropy and the spatial correlation structure [31] of the cell conductivities.

It is well established that $\mathrm{K}_{\mathrm{V}}$ must be between the arithmetic mean and the harmonic mean [37]. The p-norm average was proposed as a flexible easy-to-compute alternative because it can provide a value for $K_{V}$ between those two limits as a function of the exponent $p$ [52]:

$$
\mathrm{K}_{\mathrm{V}_{\mathrm{s}} \mathrm{p}}=\left(\frac{1}{\mathrm{~V}} \int_{\mathrm{V}} \mathrm{K}_{\mathrm{f}}^{\mathrm{p}}(\mathbf{u}) \mathrm{du}\right)^{\frac{1}{\mathrm{p}}}
$$

where $\mathrm{V}$ indicates the volume of the block; $\mathrm{K}_{\mathrm{V}, \mathrm{p}}$ is the block conductivity determined using the $\mathrm{p}$ norm, and $\mathrm{K}_{\mathrm{f}}$ represents the cell conductivities within the block. The power $\mathrm{p}$ is allowed to vary between -1 and +1 . When $\mathrm{p}$ is equal to $-1, \mathrm{~K}_{\mathrm{V}, \mathrm{p}}$ equals $\mathrm{K}_{\mathrm{h}}$; when $\mathrm{p}$ is equal to $0, \mathrm{~K}_{\mathrm{V}, \mathrm{p}}$ equals $\mathrm{K}_{\mathrm{g}}$; and when $\mathrm{p}$ is equal to $+1, \mathrm{~K}_{\mathrm{V}, \mathrm{p}}$ equals $\mathrm{K}_{\mathrm{a}}$. The challenge of $\mathrm{p}$-norm upscaling is to determine the exponent $\mathrm{p}$ that will result in a $\mathrm{K}_{\mathrm{V}, \mathrm{p}}$ that reproduces the flows observed at the fine scale. The $\mathrm{p}$ norm is a very practical method that can provide very good results in some situations $[1,38,39]$. In 
cases where the degree of heterogeneity is mild, simple averaging methods compete favorably with more sophisticated methods [53]. However, the p-norm average cannot be used without resorting to some prior numerical modeling to find the best $\mathrm{p}$ exponent [39].

$\mathrm{K}_{\mathrm{V}}$ depends not only on the cell values of flux and hydraulic head but also on the boundary conditions around the block; the fact that the same layered block will have different upscaled block values depending on whether the flow is parallel or orthogonal to it proves it. $\mathrm{K}_{\mathrm{V}}$ is said to be nonlocal [31], i.e., it depends not only on the cell values within the block but also on external factors. The simple-Laplacian is a nonlocal approach $[31,48]$ that was developed to deal with the need to determine $\mathrm{K}_{\mathrm{V}}$ considering the boundary conditions that are acting on the block boundaries. The introduction of this method represented a big improvement of the upscaling techniques when compared to local methods. Nevertheless, in this approach, the principal components of $\mathrm{K}_{\mathrm{V}}$ are assumed to be parallel to the block sides and the boundary conditions used to solve the flow at the fine-scale do not necessarily coincide with the real boundary conditions that the block may have when embedded in a larger model. [31].

To obtain the head values around the block to be upscaled, which would represent the actual boundary conditions of the block when within the studied area, it would be necessary to solve the flow equation for the entire studied area (at the fine-scale) [57]. Such a procedure is not practical because the main purpose of the upscaling is to avoid solving the flow equation at the fine scale. The Laplace-with-skin method was proposed $[18,48]$ to overcome the need for solving the flow equation over the entire model and the assumption that the principal directions of the $\mathrm{K}_{\mathrm{V}}$ tensor are parallel to the block sides. In this method, the $\mathrm{K}_{\mathrm{V}}$ is represented by a tensor that is not necessarily diagonal and flow is solved on a small numerical model containing the block plus a "skin" around it. The skin surrounding the block has information about the boundary conditions near the block, with no need for solving the entire flow problem to obtain the true boundary 
conditions at the block sides. For a three-dimensional upscaling, the Laplacian-with-skin method is described in detail in Zhou et al. [18]. Computing the block conductivity tensor using the Laplacian-with-skin method can be summarized as follows: (i) A block size is decided, and a block discretization is overlain on the fine-scale $\mathrm{K}$ realization. (ii) A skin size is decided, generally about half the size of the block. (iii) Each block and its surrounding skin is extracted from the fine-scale realization and subject to a number of local flow numerical simulations with a variety of boundary conditions that impose piezometric head gradients in different directions (it is recommended to use of at least four boundary conditions in two dimensions and eight in three dimensions [18]). (iv) From the local solution corresponding to each boundary condition, the average specific discharges and the average piezometric head gradients are computed. These average values should be related to each other through a version of Darcy's law formulated at the coarse scale. For example, in 3D, it would be the following expression:

$$
\left(\begin{array}{l}
\bar{q}_{x x} \\
\bar{q}_{y} \\
\bar{q}_{z}
\end{array}\right)=-\left(\begin{array}{lll}
\mathrm{K}_{\mathrm{xx}} & \mathrm{K}_{\mathrm{xy}} & \mathrm{K}_{\mathrm{xz}} \\
\mathrm{K}_{\mathrm{yx}} & \mathrm{K}_{\mathrm{yy}} & \mathrm{K}_{\mathrm{yz}} \\
\mathrm{K}_{\mathrm{zx}} & \mathrm{K}_{\mathrm{zy}} & \mathrm{K}_{\mathrm{zz}}
\end{array}\right)\left(\begin{array}{c}
\nabla \bar{h}_{x} \\
\nabla \bar{h}_{y} \\
\nabla \bar{h}_{z}
\end{array}\right),
$$

where $\mathrm{K}_{\mathrm{xx}}, \mathrm{K}_{\mathrm{xy}}, \mathrm{K}_{\mathrm{xz}}, \mathrm{K}_{\mathrm{yy}}, \mathrm{K}_{\mathrm{yz}}$, and $\mathrm{K}_{\mathrm{zz}}$ are the unknown components of the block conductivity tensor $K_{V}$ and $\bar{q}_{x}, \bar{q}_{y}, \bar{q}_{z}$ and $\nabla \bar{h}_{x}, \nabla \bar{h}_{y}, \nabla \bar{h}_{z}$ are the arithmetic mean of the specific discharge and the head gradients, respectively, within the block. (v) Equation (2) results in three linear equations for each boundary condition; from eight boundary conditions, it will result in an overdetermined linear system of 24 equation and 6 unknowns that is solved by least squares yielding the conductivity tensor that best associates average gradients with average fluxes for a variety of boundary conditions. 


\section{Soil description}

The tropical soil studied is from São Carlos City $\left(21^{\circ} 51^{\prime} 38^{\prime \prime} \mathrm{S}, 47^{\circ} 54^{\prime} 14^{\prime \prime} \mathrm{W}\right)$, Brazil and is found on lithologies belonging to the Botucatu Formation. It consists of fine-grained to medium-sized sandstones, with a reddish color, well-selected grains, high sphericity, very friable, or silicified. The Botucatu Formation is covered by Cenozoic sediments, which are the parent material, constituted by unconsolidated sands with a thickness ranging from $5 \mathrm{~m}$ to $7 \mathrm{~m}$ and pebbles at the base $[58,59]$. The soil in this area is highly lateritized owing to the intensive tropical weathering of the parent material [59]. The soil is mainly constituted by quartz, oxides, and hydroxides of aluminum, kaolinite, and gibbsite. At the laboratory, the soil was characterized, by the literature, as clayey sand with macropores and a double porosity fabric [60]. According to the US Soil Taxonomy classification, the soil type is an Oxisol [61], and according to the Brazilian classification system, it is a medium textured, dystrophic, red-yellow Latosol [62].

\section{Characterization of the Spatial Variability}

With the aim of characterizing the spatial variability of hydraulic conductivity, 55 undisturbed cylindrical samples of radius $0.10 \mathrm{~m}$ and height $0.15 \mathrm{~m}$ were taken in a domain of $12 \mathrm{~m}$ in the $\mathrm{x}$ direction, $7 \mathrm{~m}$ in the y-direction, and $2 \mathrm{~m}$ in the z-direction. The hydraulic conductivity was measured in the laboratory using a rigid-wall permeameter, under constant-head conditions inducing a hydraulic gradient equal to one, and at a constant temperature of $21^{\circ} \mathrm{C}$.

The histogram of the measured $\mathrm{K}$ values is best fitted by a lognormal distribution with mean and standard deviation of $1.35 \mathrm{~m} / \mathrm{d}$ and $1.65 \mathrm{~m} / \mathrm{d}$, respectively. The lognormal model implies that the natural logarithm of $\mathrm{K}(\operatorname{lnK})$ is modeled by a Gaussian distribution with mean of $-0.38(\ln (\mathrm{m} / \mathrm{d}))$ and standard deviation of $1.25(\ln (\mathrm{m} / \mathrm{d}))$. The normality of the $\ln K$ was confirmed by the 
Kolmogorov-Smirnov test with a 95\% confidence interval. Fig. 1A and Fig. 1B show the histograms and summary statistics of $\mathrm{K}$ and $\ln \mathrm{K}$, respectively.

The $\operatorname{lnK}$ spatial variability was analyzed using geostatistical techniques. The theory of geostatistics is defined as the application of regionalized variables to the study of spatial relationships. This theory, formalized by Matheron in 1963 [63], assumes that the correlation between properties (e.g., hydraulic conductivity) at different locations is some function of distance. We used the Stanford Geostatistical Modeling Software (SGeMS) [64] to compute the experimental variogram from the $55 \mathrm{~K}$ measurements using many combinations of distance and angle tolerances and bandwidths. SGeMS was then used to fit a variogram model. We could not identify any direction of preferential continuity (observed ranges in differences directions were all in the $3.9 \mathrm{~m}-4.2 \mathrm{~m}$ range), and the best fit to the experimental variogram of $\operatorname{lnK}$ was an isotropic spherical variogram

$$
\gamma(\mathbf{h})=\mathrm{c}_{0}+\mathrm{c}_{1}-\operatorname{sph}\left(|\mathbf{h}|_{z} \mathrm{a}\right)
$$

where $a$ is the range with a value of $4 \mathrm{~m}$ in all directions, $\mathbf{h}$ is the directional lag distance, $|\cdot|$ is the modulus operator, and $\operatorname{sph}()$ is the spherical function [65]. The total variance, $\mathrm{c}_{0}+\mathrm{c}_{1}$, of $\ln K$ is $1.57(\ln (\mathrm{m} / \mathrm{d}))^{2}$ and represents a moderate heterogeneous media. No nugget $\left(\mathrm{c}_{0}\right)$ was used to fit the model. The experimental variogram and the fitted model are shown in Fig. 2.

\section{Simulation of the Hydraulic Conductivity Random Fields}

Gaussian random fields are completely defined by their first two moments, mean and covariance. A Gaussian random field is represented by the infinite set of multivariate Gaussian distributions that can be built with any combination of points in some spatial domain $[66,67]$. Within the framework of the random field theory, $\ln \mathrm{K}$ is modeled as a random variable at each location in space, and the resulting random field is assumed second-order stationary, i.e., the expected value 
of all random variables is constant, and the covariance of any pair of random variables is translation independent. Under these assumptions, 70 equally likely realizations (regionalized fields) were generated using the Sequential Gaussian Simulation (SGS) algorithm implemented in the code GCOSIM3D [68], with the mean $\operatorname{lnK}$ computed from the data and the variogram function shown in Fig. 2. These regionalized fields were, by construction, isotropic and conditioned to the 55 measured data, that is, realizations not only reproduced the statistical spatial patterns of the data but also honored the data at their locations. The honor to the measured data is achieved using the sequential simulation decomposition of a n-variate probability distribution as the product of $\mathrm{n}$ univariate conditional distributions, whereby drawing a realization from the n-variate distribution can be replaced by drawing (sequentially) from $\mathrm{n}$ univariate distributions [23].

The random field domain is a parallelepiped with dimensions of $\mathrm{x}=24 \mathrm{~m}, \mathrm{y}=16 \mathrm{~m}$, and $\mathrm{z}=8 \mathrm{~m}$, and it is discretized into $3,072,000$ cubic cells of side $0.1 \mathrm{~m}$ to keep the numerical cells with a magnitude similar to the scale of the permeameter measurements. We have generated realizations within a domain twice the size of the studied area. The justification for the size of the generated domain is that the upscaling technique requires an outer skin composed by a certain number of additional elements. However, only the inner domain consisting of $\mathrm{x}=12 \mathrm{~m}, \mathrm{y}=8 \mathrm{~m}$, and $\mathrm{z}=4$ $\mathrm{m}$ dimensions will be used to simulate groundwater flow and to perform upscaling [48]. The 70 conditional realizations make up a model of the spatial uncertainty of $\mathrm{K}$ at the fine scale; they will be used to analyze the efficiency of the upscaling techniques. Fig. 3 shows realizations numbers 1 and 70 . Before performing the groundwater flow numerical simulation, the $\operatorname{lnK}$ random fields were, obviously, back-transformed into $\mathrm{K}$ fields. 


\section{Groundwater Flow Numerical Modeling at the Fine Scale}

Steady-state flow in the absence of sinks and sources of an incompressible fluid in a saturated porous media was modeled. Under these conditions, the flow equation at the fine scale can be expressed using the following equation [69]:

$$
\sum_{\mathrm{i}=1}^{3} \sum_{\mathrm{j}=1}^{3} \frac{\partial}{\partial \mathrm{x}_{\mathrm{i}}}\left(\mathrm{K}_{\mathrm{ij}}(\overrightarrow{\mathrm{x}}) \frac{\partial \mathrm{h}(\overrightarrow{\mathrm{x}})}{\partial \mathrm{x}_{\mathrm{i}}}\right)=0
$$

Equation (4) results from the combination of Darcy's Law and the continuity equation, where $h$ is the piezometric head and $\mathbf{K}$ is a second-order symmetric hydraulic conductivity tensor at the fine scale.

As the observed spatial variability of $\mathrm{K}$ is isotropic and it is well known [70] that spatial correlation anisotropy is, among other reasons, the responsible for flow anisotropy, we have decided to model fine-scale conductivities as isotropic to flow, that is, as scalar values. Each of the 70 realizations of $\mathrm{K}$ at the fine scale was used as input to 70 numerical models. For each realization, three-dimensional flow was solved by the finite element method (FEM) using the preconditioned conjugate-gradient method using FEFLOW 7.1 [71].

A MATLAB routine was written to manage the entire modeling process. This routine couples the execution of GCOSIM3D and FEFLOW to automatically perform the generation of the realizations and the flow simulations. MATLAB calls GCOSIM3D to generate the random fields and reformats the output files to adequate them to the input format of FEFLOW. The FEFLOW runs were configured and executed in MATLAB using the command-line mode with a code written in the Python language using interface manager API functions.

A finite element mesh was generated using the transport mapping method (also called transfinite interpolation) on a rectangular discretization of the grid into $120 \times 80 \times 40$ cuboid cells of $0.1 \mathrm{~m} \mathrm{x}$ 
$0.1 \mathrm{~m} \times 0.1 \mathrm{~m}$ for a total of 384000 elements. Confined flow was modeled on the realizations with no flow boundary conditions at the top and bottom faces of the parallelepiped, and prescribed constant heads of $50 \mathrm{~m}$ at the right face and $38 \mathrm{~m}$ at the left side, forcing flow from left to right. The hydraulic gradient induced by these constant head boundaries is one, replicating laboratory conditions. From the solution of the flow equation, we retrieved the hydraulic head in each node of the model, and the specific discharge in the $\mathrm{x}$-direction $\left(\mathrm{q}_{\mathrm{x}}\right)$ through a control plane orthogonal to the flow direction, for each realization.

\section{Hydraulic Conductivity Upscaling}

In this section, the flow equation at the coarse scale is presented, and the details of the upscaling are defined.

\subsection{Flow equation at the coarse scale}

At the coarse scale, block conductivity $\left(\mathrm{K}_{\mathrm{V}}\right)$ is defined, using an upscaled version of Darcy's law, as the quantity that relates the average specific discharge within a given block to the average head gradient $\overline{\boldsymbol{q}}=-\mathbf{K}_{\mathrm{V}} \nabla \bar{h}$, where the bar denotes volumetric average. $\mathbf{K}_{\mathrm{V}}$ is a symmetric and positive

definite three-dimensional full tensor, which will be considered as scalar in this paper [72]. The decision of model $\mathrm{Kv}$ as a scalar was made after performing several tests and checking that the differences in $\mathrm{Kv}$ values in the $\mathrm{x}, \mathrm{y}$, and $\mathrm{z}$ directions were not significant; this is an expected result because the underlying fine-scale realizations were modeled as spatially isotropic random fields [70].

\subsection{Upscaling Design}

Each of the 70 realizations of the $\mathrm{K}$ fields generated at the fine-scale was upscaled with the Laplacian-with-skin method using the code provided by Zhou et al. [18] after a minor 
modification that allowed the automatic upscaling of all realizations. A MATLAB code was written with the objective of coupling GCOSIM3D, FEFLOW, and the upscaling code. We have performed upscaling with cubic block sizes $2,4,5,8,10$, and 40 times the side size of the block at the fine scale $(0.1 \mathrm{~m})$. Additionally, an upscale with a unique block with the same size as the entire domain (12 $\mathrm{m} \times 8 \mathrm{~m} \times 4 \mathrm{~m})$ was performed. Table 1 shows the block side size of the upscaled models, the total number of elements for each model, and the reduction factor in the number of elements when compared with the fine scale.

The size of the outer skin was set equal to half the block size in each direction to upscaling each individual block. Previous work showed that this skin size is adequate to upscale hydraulic conductivity [18]. We have performed some initial tests with different skin sizes, and it was found that this size of skin is adequate for our problem.

It is important to clarify that the generated domains have dimensions of $\mathrm{x}=24 \mathrm{~m}, \mathrm{y}=16 \mathrm{~m}$, and $\mathrm{z}=8 \mathrm{~m}$ because the maximum dimension of the block side size was equal to the entire domain (12 $\mathrm{m} \times 8 \mathrm{~m} \times 4 \mathrm{~m}$ ), and we have opted to use a skin equal to half the block size of each side of the model. Only the inner area of the $\mathrm{x}=12 \mathrm{~m}, \mathrm{y}=8 \mathrm{~m}$, and $\mathrm{z}=4 \mathrm{~m}$ dimensions was used to verify the efficiency of the upscaling approach; however, the external area was needed to compute the block conductivities when using the Laplacian-with-skin approach.

The conductivity was computed at block centers, and the FEM was used to solve the groundwater flow equation. After isolating each block to be upscaled (with the corresponding skin), groundwater flow was solved for nine different sets of boundary conditions; these boundary conditions were chosen so that the overall head gradient through the block is parallel to the directions given by the vectors $(1,0,0),(0,1,1),(1,1,0),(0,1,0),(0,0,1),(1,1,0),(1,0,1),(-$ $1,0,1)$, and $(0,-1,1)$. All the analyses mentioned hereafter were made for all realizations and all block sizes mentioned in Table 1. Once the block values have been calculated, they were 
assembled to build the coarse-scale numerical model, and the groundwater flow equation was solved with the boundary conditions same as those used for the fine-scale numerical model. Fig. 4 shows the upscaled $\ln K$ realizations for the fine-scale realization number 1 for all block side sizes considered.

To evaluate upscaling performance, the hydraulic head obtained in each node of each flow model at the coarse scale was compared with the corresponding value obtained after solving the flow model at the fine scale. As we have 70 realizations and many nodes in each realization, we opted to show these results in terms of average relative bias of head $\left(\mathrm{RB}_{\mathrm{h}}\right)$ for each realization and block size, given by the equation

$$
\mathrm{RB}_{\mathrm{h}}=\frac{1}{\mathrm{NN}} \sum_{\mathrm{i}=1}^{\mathrm{NN}}\left\lceil\left[\frac{\mathrm{h}_{\mathrm{f}, \mathrm{i}}-\mathrm{h}_{\mathrm{c}, \mathrm{i}}}{\mathrm{h}_{\mathrm{f}, \mathrm{i}}}\right] .100\right.
$$

where $\mathrm{NN}$ is the total number of coarse model nodes for the given block size and realization; $\mathrm{h}_{\mathrm{f}, \mathrm{i}}$ is the hydraulic head obtained from the fine-scale numerical model for node $\mathrm{i}$; and $\mathrm{h}_{\mathrm{c}, \mathrm{i}}$ is the hydraulic head obtained from the coarse-scale model at the same node.

The reproduction of the mean specific discharge in the $\mathrm{x}$-direction $\left(\mathrm{q}_{\mathrm{x}}\right)$ at a control plane orthogonal to flow was evaluated using the relative bias of specific discharge $\left(R_{\mathrm{q}}\right)$, given by the equation

$$
\mathrm{RB}_{\mathrm{q}}=\frac{1}{\mathrm{NR}} \sum_{\mathrm{i}=1}^{\mathrm{NR}}\left\lceil\frac{\mathrm{q}_{\mathrm{f}, \mathrm{i}}-\mathrm{q}_{\mathrm{c}, \mathrm{i}}}{\mathrm{q}_{\mathrm{f}, \mathrm{i}}}\right\rceil .100
$$

where NR is the number of realizations; $\mathrm{q}_{\mathrm{f}, \mathrm{i}}$ is the specific discharge through the control plane obtained from the fine-scale numerical model for realization $\mathrm{i}$; and $\mathrm{q}_{\mathrm{c}, \mathrm{i}}$ is the specific discharge through the same control plane from the coarse-scale model for the same realization. One would expect that the $\mathrm{RB}_{\mathrm{q}}$ would increase with block size. 
After determining the block values with the rigorous and time-consuming Laplace-with-skin approach, our next objective was to determine if these values could be approximated with the simple local technique of $\mathrm{p}$-norm averaging. For the evaluation of the $\mathrm{p}$ exponent (which, presumably, should be a function of the block side), we perform an optimization in MATLAB using the function "fminbnd," which is based on a golden section search and parabolic interpolation to minimize the objective function

$\operatorname{error}(\mathrm{p})=\sum_{i=1}^{N R} \sum_{\mathrm{I}=1}^{\mathrm{NN}}\left|\ln \mathrm{K}_{\mathrm{V}_{\mathrm{i}, \mathrm{lij}}}-\ln \mathrm{K}_{\mathrm{V}, \mathrm{p}, \mathrm{j}, \mathrm{j}}\right|$

where $\mathrm{K}_{\mathrm{V}, ., i j}$ is the block value computed with the Laplacian-with-skin method, and $\mathrm{K}_{\mathrm{V}, p, i j}$ is the value computed as a p-norm average. The exponent was constrained to be between -1 and +1 (corresponding to the harmonic and arithmetic averages). Once the best $\mathrm{p}$ exponent was

determined, groundwater flow at the coarse scale was solved with the optimal $\mathrm{K}_{\mathrm{V}, p}$ values using the boundary conditions same as those used previously. In addition, and for comparison purposes, flow was also solved with the block values obtained with $\mathrm{p}$ equal to $-1,0$ and 1 , that is, with block values equal to the harmonic, geometric and arithmetic averages of the cell values within the block.

\section{Results and discussion}

\subsection{Reproduction of the flow at the coarse scale}

In this section, the results of the upscaling using the Laplacian-with-skin method will be discussed. Fig. 5 shows the comparison of the specific discharge in the $\mathrm{x}$-direction $\left(\mathrm{q}_{\mathrm{x}}\right)$ obtained from the model performed at the fine scale versus the results obtained from the model built with the block conductivity values computed by upscaling using the Laplacian-with-skin method. We show only the results in the $\mathrm{x}$-direction because the boundary conditions imposed in the model 
force the flow in that direction. We expect that the results regarding fluxes in the y- or zdirections would have had similar changes in the boundary conditions to force flow in those directions. The relative bias of the specific discharge increases with the increase in the block size side, except for a block side size equal to $2 \mathrm{~m}$ that presented slightly higher $\mathrm{RB}_{\mathrm{q}}$ than a block side size equal to $4 \mathrm{~m}$. Given that the skin size is half the block side size, blocks greater than $2 \mathrm{~m}$ will result in blocks greater than the correlation length $(4 \mathrm{~m})$, and in that situation, the flow behavior is mainly determined by the conductivities within the blocks and the influence of the skin is apparently reduced [48]. The increase in the $\mathrm{RB}_{\mathrm{q}}$ with the block side size is due to the smoothing of the heterogeneity caused by the upscaling procedure. The relative variations of the variance and the mean of the block conductivities as a function of the block side size are shown in Fig. 6. A reduction of up to $83.5 \%$ of the variance with the increase in block side sizes was observed. This smoothing of the heterogeneity can be clearly verified as mentioned in previous research $[16,73,74]$. The block side sizes up to $1.0 \mathrm{~m}$ resulted in a small increase of the mean of up to $4 \%$. The higher effect was obtained for the block side sizes equal to 4 and $12 \mathrm{~m}$, where the increase in the mean was $17 \%$ and $23 \%$, respectively. The increase in the mean was also mentioned by other authors [75], which attribute it to the impact of high conductivity features in $K_{V}$ when the block increases.

The reproduction of the specific discharge at the coarse scale is good given the relative small errors obtained, indicating that the upscaling method works well, in consonance with the results obtained by other authors [18,32]. Upscaling implies smoothing and loss of heterogeneity; we have tested upscaling for the purpose of reproducing the average flux crossing the model, and for this purpose, the upscaling method is very effective. Previous works focused on capturing some local features show that for blocks larger than half the correlation length, the influence of these local features is lost. [33]. Other works focused on magnitudes at the scale of the model have 
obtained good results with blocks up to three times the correlation length (as is the case for our most extreme upscaling) [39]. In our work, the reproduction of the total flow crossing the model is good for all block sizes, although the $\mathrm{RB}_{\mathrm{q}}$ deteriorates with the block size. These results are very encouraging because we can compute the total flow through the domain of study using a model with blocks of $4 \mathrm{~m}$, which has 64,000 times less elements than the model built at the scale at which the data are collected.

Continuing with the investigation of the efficiency of the upscaling using the Laplacian-with-skin method, the relative bias of the head, $\mathrm{RB}_{\mathrm{h}}$, for each realization and all block side sizes is shown in Fig. 7. For the block side size with the same size of the domain, the $\mathrm{RB}_{\mathrm{h}}$ is always zero, as there are only eight nodes at the coarse scale and are coincident with the boundary conditions at the fine scale. The $R B_{h}$ is greater when the block side size increases. The largest $R B_{h}$ occurs for the block with a side size equal to the correlation length, yet its value is very small, with the maximum $\mathrm{RB}_{\mathrm{h}}$ below $0.9 \%$. The small errors of the $\mathrm{RB}_{\mathrm{q}}$ is also due to the small spatial variability of the piezometric heads.

Deterministic models disregard uncertainty. However, uncertainty is inherent to heterogeneity when this is characterized from a limited set of observations. Such an uncertainty on conductivity propagates through the groundwater flow model onto uncertainty on the results of the model, such as the specific discharges. We have evaluated the uncertainty on specific discharges by analyzing their statistics as computed from 70 realizations (which are equally likely representations of reality given the random field model adopted) of K. Further, we have analyzed how this uncertainty changes after performing upscaling. Table 2 shows the statistics of $\mathrm{q}_{\mathrm{x}}$ at the fine scale and after upscaling for the different block sizes. From Table 2, we see that upscaling not only produces models with a small $\mathrm{RB}_{\mathrm{q}}$ but also preserves the uncertainty of $\mathrm{q}_{\mathrm{x}}$ at the fine scale, even for a block size equal to the entire domain. 
A common practice in geotechnical investigations is to build homogeneous models using some average value of the measured data. For this reason, and for comparison purposes, we have also computed the single specific discharge associated with homogeneous models. In these models, we used conductivities equal to the harmonic, geometric, and arithmetic averages of $\mathrm{K}$. The resulting $\mathrm{q}_{\mathrm{x}}$ values were equal to $0.29 \mathrm{~m} / \mathrm{d}$ for the harmonic mean, $0.68 \mathrm{~m} / \mathrm{d}$ for the geometric mean, and $1.32 \mathrm{~m} / \mathrm{d}$ for the arithmetic mean. When these values are plotted in the cumulative frequency distribution function of the $\mathrm{q}_{\mathrm{x}}$ at the fine scale (Fig. 8), the importance of the stochastic modeling is obvious. The probability of $\mathrm{q}_{\mathrm{x}}$ being larger than the value obtained using the harmonic mean is $100 \%$. When $\mathrm{K}$ is computed using the geometric mean, there is a probability of $66 \%$ that the $\mathrm{q}_{\mathrm{x}}$ calculated using this $\mathrm{K}$ value be exceeded. Finally, the probability of $\mathrm{q}_{\mathrm{x}}$ being smaller than the value obtained using the arithmetic mean is almost $86 \%$. These results demonstrate that the use of a unique $\mathrm{K}$ value with no consideration of the spatial correlation of the $\mathrm{K}$ can result in a specific discharge not representative of the real flow and potentially induce large errors in the calculation of fluxes.

\subsection{Variation of the p-exponent with the block size}

The p-exponent that produces the best approximation of $\mathrm{Kv}, l$ by $\mathrm{Kv}, p$ was computed for each block side size after minimizing equation (7). Fig. 9 shows the variation of the best p-exponent with the variation of the block side size. We can notice that the p-exponent increases up to a limit and then stabilizes. The p-exponent lies between 0.26 and 0.29 . This variation can be fitted with the following exponential model, with an error on p below $5 \%$ :

$$
\mathrm{p}_{\text {model }}=-3.27 \exp (-7.72 \text { BlockSize- } 0.79)+0.28 \text {. }
$$

Selvadurai and Selvadurai [76] found, for a deterministic isotropic three-dimensional upscaling, that the geometric mean $(p=0)$ was the best $p$-norm to compute $K_{V}$ [76]. Desbarats [39] found, 
for a case when the block side size was equal to three times the range, the best $\mathrm{p}$-exponent was found to be $1 / 3$ in a 3D mildly heterogeneous and statically isotropic media with arbitrary boundary conditions [39].

The variation of the p-exponent with the number of realizations was also investigated, and it was noticed that when computed using less than 20 realizations, the p-exponent presented great oscillation. When the number of realization was bigger than 20 , the p-exponent tends to stabilize. The variance of the $\mathrm{K}$ random fields will also influence the $\mathrm{p}$-exponent value, and future research may be needed to analyze this behavior. In preliminary analyses in synthetic $\mathrm{K}$ fields, we have found that the p-exponent tends to increase with the magnitude of the variance for isotropic fields. For anisotropic fields, the block value must be a tensor and the p-exponent that approximates the component in the direction of maximum continuity increases with variance, but it decreases for the component in the direction of minimum continuity.

The reproduction of the $\mathrm{q}_{\mathrm{x}}$ obtained from the model performed at the fine scale was compared with the results obtained after upscaling using a p-norm, and the results are shown in Fig. 10. Similarly, as in Fig. 5, the relative bias of the specific discharge, $\mathrm{RB}_{\mathrm{q}}$, increases with the increase in the block side size. For block side sizes up to $1.0 \mathrm{~m}$, the $\mathrm{RB}_{\mathrm{q}}$ obtained with the Laplacian-withskin method and p-norm are almost equal. Block side sizes more than $1.0 \mathrm{~m}$ resulted in different $\mathrm{RB}_{\mathrm{q}}$, and for the block side size equal to $12.0 \mathrm{~m}$, the $\mathrm{RB}_{\mathrm{q}}$ was $17 \%$ with the p-norm and $27 \%$ with the Laplacian-with-skin method. The quality of the upscaling can also be checked by the very good agreement between the $\mathrm{q}_{\mathrm{x}}$ values obtained at the fine scale and at the coarse scale.

Fig. 11 shows the relative bias of head, $\mathrm{RB}_{\mathrm{h}}$, for all block side sizes and all realizations obtained with the p-norm using the best p-exponent. As mentioned before in the results of the Laplacianwith-skin method, the relative bias of the piezometric head, $\mathrm{RB}_{\mathrm{h}}$, is always zero for the block with a size same as that of the entire domain. With the increase in the block side size, the $R_{h}$ 
increases, reflecting the effects of the reduction in the heterogeneity. In this situation, the $\mathrm{RB}_{\mathrm{h}}$ was greater than the one obtained with the Laplacian-with-skin method, but yet the maximum $\mathrm{RB}_{\mathrm{h}}$ was $1.44 \%$, a very satisfactory reproduction of the flow at the coarse scale.

The specific discharges in the $\mathrm{x}$-direction $\left(\mathrm{q}_{\mathrm{x}}\right)$ computed with block values obtained using $\mathrm{p}$ norms equal to -1 (harmonic mean), 0 (geometric mean), and 1 (arithmetic mean) were compared with the values computed on the fine-scale model and are shown in Figs 12, 13, and 14. The purpose of this comparison is to show the errors that could be incurred when using an incorrect pexponent. The $\mathrm{RB}_{\mathrm{q}}$ increases with the increase in the block side size. For block side sizes equal to $0.2 \mathrm{~m}$ and $0.4 \mathrm{~m}$, all the upscaling procedures seem to be adequate, the reason being that the heterogeneity within the blocks at this size is small and all p-norms yield similar values. In general, the geometric mean (Fig. 13) resulted in the smallest errors and the arithmetic mean (Fig. 14) in the largest ones. Moreover, in general, $q_{x}$ was underestimated by the harmonic mean (Fig. 12) and overestimated by the arithmetic mean (Fig 14.). We also analyzed the reproduction of $h$ when upscaling using $\mathrm{p}=-1, \mathrm{p}=0$, and $\mathrm{p}=+1$, and we found that the $\mathrm{RB}_{\mathrm{h}}$ increases with the block side size and that the smallest $\mathrm{RB}_{\mathrm{h}}$ was obtained with the geometric mean.

These results are of interest for future applications in which there is an interest in performing block conductivity upscaling in tropical soils such as the one studied here. The p-exponent could be read from the fitted curve given by equation (8) and p-norm upscaling was used to compute block values quickly. However, the application of this approach to a new soil would require first to perform an analysis similar to the one performed here to find out the best p-exponents before conducting the upscaling with the p-norm average.

The workflow would be as follows:

Collect samples in the area of interest and characterize their spatial variability. 
Perform nonlocal upscaling analyses to investigate whether the quantities of interest (in our case it was total flow crossing the domain, and piezometric heads at discretization nodes) are well reproduced by the upscaled models.

Determine the best $\mathrm{p}$ exponent that produces results similar to those obtained with the nonlocal techniques using some minimization technique.

Generate realizations at the small scale using the algorithm of your choice.

Use the p-exponent found before to build quickly coarse models using p-norm upscaling, and use the coarse models for the study.

\section{Conclusions}

Stochastic three-dimensional upscaling of hydraulic conductivity using the Laplacian-with-skin method was performed in a flow model of a tropical soil from Brazil, where conductivity had been measured at 55 locations over the support of rigid laboratory permeability. Eight different block sizes were analyzed. Deterministic analyses using simple averaging of $\mathrm{K}$ were also done to show the importance of using a stochastic approach. The upscaling efficiency with the variation of the block side size was investigated. The behavior of the p-exponent of the p-norm with the increase in the block side size was also studied.

Upscaling conductivities using the Laplacian-with-skin method gave excellent results showing small relative bias for the quantities computed both at the fine and coarse scales, even for a single block with the size of the entire domain. The relative biases of specific discharge and of piezometric head tend to increase with block side size. The variance of specific discharge tends to decrease with the increase in the block side sizes, reflecting the heterogeneity smoothing effect of upscaling. The mean of the specific discharge increased with block side size. The uncertainty in $\mathrm{q}_{\mathrm{x}}$ is well captured by the upscaled $\mathrm{K}$ values. The analysis of the variation of the p-exponent with 
the block side sizes showed that the p-exponent increases with block size up to the block side is $0.8 \mathrm{~m}$ and then it remains stable about $\mathrm{p}=0.29$. This variation was fitted with an exponential expression that gives $\mathrm{p}$ as a function of block side. The upscaling using the p-exponent that best reproduces the Laplacian-derived $\mathrm{Kv}, l$ resulted in very good reproduction of the flow even for large block side sizes. The results obtained in this work allow the use of the p-norm in a practical, reliable, and fast way for $\mathrm{K}$ upscaling in tropical soils of the studied region. The workflow for the application of the proposed method in other soils is also provided. Finally, this paper shows the errors that could be incurred when using certain deterministic analysis for the analysis of groundwater flow and the importance to rely on well-proven methods such as the Laplacian-withskin method for upscaling in a geotechnical context.

\section{Acknowledgments}

The authors thank the financial support by the Brazilian National Council for Scientific and Technological Development (CNPq) (Project 401441/2014-8). The doctoral fellowship award to the first author by the Coordination of Improvement of Higher Level Personnel (CAPES) is gratefully acknowledged. The first author thanks the International Mobility Grant awarded by CNPq and Santander mobility. The authors also thank DHI-WASI for providing a FEFLOW Software license.

\section{References}

[1] Elkateb T, Chalaturnyk R. An overview of soil heterogeneity: quantification and implications on geotechnical field problems. Can Geotech 2003. doi:10.1139/t02-090.

[2] Chapuis RP, Dallaire V, Marcotte D, Chouteau M, Acevedo N, Gagnon F. Evaluating the hydraulic conductivity at three different scales within an unconfined sand aquifer at 
Lachenaie, Quebec. Can Geotech J 2005;42:1212-20. doi:10.1139/t05-045.

[3] Sánchez-Vila X, Carrera J, Girardi JP. Scale effects in transmissivity. J Hydrol 1996;183:1-22. doi:10.1016/S0022-1694(96)80031-X.

[4] Lacasse S, Nadim F. Uncertainties in characterising soil properties. Publ - Norges Geotek Inst 1996;201:49-75.

[5] DeGroot DJ, Baecher GB. Estimating Autocovariance of In-Situ Soil Properties. J Geotech Eng 1993;119:147-66. doi:10.1061/(ASCE)0733-9410(1993)119:1(147).

[6] Scheibe T, Yabusaki S. Scaling of flow and transport behavior in heterogeneous groundwater systems. Adv Water Resour 1998;22:223-38. doi:10.1016/S03091708(98)00014-1.

[7] Huang J, Griffiths DV. Modelling spatial variability in geotechnical engineering. Georisk Assess Manag Risk Eng Syst Geohazards 2016;10:1-1. doi:10.1080/17499518.2015.1123727.

[8] Geetha Manjari K, Sivakumar Babu GL. Probabilistic analysis of groundwater and radionuclide transport model from near surface disposal facilities. Georisk Assess Manag Risk Eng Syst Geohazards 2017:1-14. doi:10.1080/17499518.2017.1329538.

[9] Huang J, Griffiths D V., Fenton GA. Probabilistic Analysis of Coupled Soil Consolidation. J Geotech Geoenvironmental Eng 2010;136:417-30. doi:10.1061/(ASCE)GT.19435606.0000238 .

[10] Chapuis RP. Numerical modeling of reservoirs or pipes in groundwater seepage. Comput Geotech 2009;36:895-901. doi:10.1016/j.compgeo.2009.01.005.

[11] Blake JR, Renaud J-P, Anderson MG, Hencher SR. Prediction of rainfall-induced transient water pressure head behind a retaining wall using a high-resolution finite element model. Comput Geotech 2003;30:431-42. doi:10.1016/S0266-352X(03)00055-7. 
[12] Feng S-J, Zheng Q-T, Xie H-J. A model for gas pressure in layered landfills with horizontal gas collection systems. Comput Geotech 2015;68:117-27. doi:10.1016/j.compgeo.2015.04.005.

[13] Zhou H, Gómez-Hernández JJ, Hendricks Franssen H-J, Li L. An approach to handling non-Gaussianity of parameters and state variables in ensemble Kalman filtering. Adv Water Resour 2011;34:844-64. doi:10.1016/j.advwatres.2011.04.014.

[14] Li L, Zhou H, Gómez-Hernández JJ, Hendricks Franssen H-J. Jointly mapping hydraulic conductivity and porosity by assimilating concentration data via ensemble Kalman filter. J Hydrol 2012;428-429:152-69. doi:10.1016/j.jhydrol.2012.01.037.

[15] Vogel H-J, Roth K. Moving through scales of flow and transport in soil. J Hydrol 2003;272:95-106. doi:10.1016/S0022-1694(02)00257-3.

[16] Vik B, Bastesen E, Skauge A. Journal of Petroleum Science and Engineering Evaluation of representative elementary volume for a vuggy carbonate rock - Part: Porosity , permeability , and dispersivity. J Pet Sci Eng 2013;112:36-47. doi:10.1016/j.petrol.2013.03.029.

[17] Dousset S, Thevenot M, Pot V, Šimunek J. Evaluating equilibrium and non-equilibrium transport of bromide and isoproturon in disturbed and undisturbed soil columns. J Contam 2007;94:261-76. doi:10.1016/j.jconhyd.2007.07.002.

[18] Zhou H, Li L, Jaime Gómez-Hernández J. Three-dimensional hydraulic conductivity upscaling in groundwater modeling. Comput Geosci 2010;36:1224-35. doi:10.1016/j.cageo.2010.03.008.

[19] Li L, Zhou H, Gómez-Hernández JJ. Transport upscaling using multi-rate mass transfer in three-dimensional highly heterogeneous porous media. Adv Water Resour 2011;34:47889. doi:10.1016/j.advwatres.2011.01.001. 
[20] Cassiraga EF, Fernàndez-Garcia D, Gómez-Hernández JJ. Performance assessment of solute transport upscaling methods in the context of nuclear waste disposal. Int J Rock Mech Min Sci 2005;42:756-64. doi:10.1016/j.jirmms.2005.03.013.

[21] Gómez-Hernández JJ, Cassiraga EF. Theory and Practice of Sequential Simulation, 1994, p. 111-24. doi:10.1007/978-94-015-8267-4_10.

[22] Journel AG, Gomez-Hernandez JJ. Stochastic Imaging of the Wilmington Clastic Sequence. SPE Form Eval 1993;8:33-40. doi:10.2118/19857-PA.

[23] Goovaerts P. Geostatistical modelling of uncertainty in soil science. Geoderma 2001;103:3-26. doi:10.1016/S0016-7061(01)00067-2.

[24] Griffiths D V, Fenton GA. Three-Dimensional Seepage through Spatially Random Soil. J Geotech Geoenvironmental Eng 1997;123:153-60. doi:10.1061/(ASCE)10900241(1997)123:2(153).

[25] Cho SE. Probabilistic stability analysis of rainfall-induced landslides considering spatial variability of permeability. Eng Geol 2014;171:11-20. doi:10.1016/j.enggeo.2013.12.015.

[26] Reddy KR, Kulkarni HS, Srivastava A, Babu GLS. Influence of Spatial Variation of Hydraulic Conductivity of Municipal Solid Waste on Performance of Bioreactor Land fi 11. J Geotech Geoenvironmental Eng 2013;139:1968-72. doi:10.1061/(ASCE)GT.19435606.0000930.

[27] Zhu H, Zhang LM, Zhang LL, Zhou CB. Two-dimensional probabilistic infiltration analysis with a spatially varying permeability function. Comput Geotech 2013;48:249-59. doi:10.1016/j.compgeo.2012.07.010.

[28] Liu L-L, Cheng Y-M, Jiang S-H, Zhang S-H, Wang X-M, Wu Z-H. Effects of spatial autocorrelation structure of permeability on seepage through an embankment on a soil foundation. Comput Geotech 2017;87:62-75. doi:10.1016/j.compgeo.2017.02.007. 
[29] Tuli A, Hopmans JW, Rolston DE, Moldrup P. Comparison of Air and Water Permeability between Disturbed and Undisturbed Soils. Soil Sci Soc Am J 2005;69:1361. doi:10.2136/sssaj2004.0332.

[30] Osinubi K 'J., Nwaiwu CM. Hydraulic Conductivity of Compacted Lateritic Soil. J Geotech Geoenvironmental Eng 2005;131:1034-41. doi:10.1061/(ASCE)10900241(2005)131:8(1034).

[31] Wen X-H, Gómez-Hernández JJ. Upscaling hydraulic conductivities in heterogeneous media: An overview. J Hydrol 1996;183:ix-xxxii. doi:10.1016/S0022-1694(96)80030-8.

[32] Li L, Zhou H, Gómez-Hernández JJ. A comparative study of three-dimensional hydraulic conductivity upscaling at the macro-dispersion experiment (MADE) site, Columbus Air Force Base, Mississippi (USA). J Hydrol 2011;404:278-93. doi:10.1016/j.jhydrol.2011.05.001.

[33] Huang J, Griffiths DV. Determining an appropriate finite element size for modelling the strength of undrained random soils. Comput Geotech 2015;69:506-13. doi:10.1016/j.compgeo.2015.06.020.

[34] Sánchez-Vila X, Girardi JP, Carrera J. A Synthesis of Approaches to Upscaling of Hydraulic Conductivities. Water Resour Res 1995;31:867-82. doi:10.1029/94WR02754.

[35] Matheron G. Elements pour une théorie des milieux poreux 1967.

[36] Gómez-Hernández JJ, Wen X-H. Probabilistic assessment of travel times in groundwater modeling. Stoch Hydrol Hydraul 1994;8:19-55. doi:10.1007/BF01581389.

[37] Cardwell WT, Parsons RL. Average Permeabilities of Heterogeneous Oil Sands. Trans AIME 1945;160:34-42. doi:10.2118/945034-G.

[38] Gomez-Hernandez JJ, Gorelick SM. Effective groundwater model parameter values: Influence of spatial variabiity of hydraulic conductivity, leackance, and recharge. Water 
Resour Res 1989;25:405-19.

[39] Desbarats AJ. Spatial averaging of hydraulic conductivity in three-dimensional heterogeneous porous media. Math Geol 1992;24:249-67. doi:10.1007/BF00893749.

[40] Desbarats AJ. Numerical estimation of effective permeability in sand-shale formations. Water Resour Res 1987;23:273-86. doi:10.1029/WR023i002p00273.

[41] Warren J, Price H. Flow in Heterogeneous Porous Media. Soc Pet Eng J 1961;1:153-69. doi:10.2118/1579-G.

[42] Rubin Y, Gómez-Hernández JJ. A stochastic approach to the problem of upscaling of conductivity in disordered media: Theory and unconditional numerical simulations. Water Resour Res 1990;26:691-701. doi:10.1029/WR026i004p00691.

[43] Sarris TS, Paleologos EK. Numerical investigation of the anisotropic hydraulic conductivity behavior in heterogeneous porous media. Stoch Environ Res Risk Assess 2004;18:188-97. doi:10.1007/s00477-003-0171-3.

[44] Dewandel B, Maréchal JC, Bour O, Ladouche B, Ahmed S, Chandra S, et al. Upscaling and regionalizing hydraulic conductivity and effective porosity at watershed scale in deeply weathered crystalline aquifers. J Hydrol 2012;416-417:83-97. doi:10.1016/j.jhydrol.2011.11.038.

[45] Fleckenstein JH, Fogg GE. Efficient upscaling of hydraulic conductivity in heterogeneous alluvial aquifers. Hydrogeol J 2008;16:1239-50. doi:10.1007/s10040-008-0312-3.

[46] Zhang Y, Gable CW, Sheets B. Equivalent hydraulic conductivity of three-dimensional heterogeneous porous media: An upscaling study based on an experimental stratigraphy. J Hydrol 2010;388:304-20. doi:10.1016/j.jhydrol.2010.05.009.

[47] Narsilio GA, Buzzi O, Fityus S, Yun TS, Smith DW. Upscaling of Navier-Stokes equations in porous media: Theoretical, numerical and experimental approach. Comput 
Geotech 2009;36:1200-6. doi:10.1016/j.compgeo.2009.05.006.

[48] Gómez-Hernandez J. A stochastic approach to the simulation of block conductivity fields conditional upon data measured at a smaller scale. Stanford University, 1990.

[49] HUANG J, GRIFFITHS DV. One-dimensional consolidation theories for layered soil and coupled and uncoupled solutions by the finite-element method. Géotechnique 2010;60:709-13. doi:10.1680/geot.08.P.038.

[50] Renard P, de Marsily G. Calculating equivalent permeability: a review. Adv Water Resour 1997;20:253-78. doi:10.1016/S0309-1708(96)00050-4.

[51] Sanchez-Vila X, Guadagnini A, Carrera J. Representitive Hydraulic Conductivities in Saturated Groundwater Flow. Rev 2006;44:1-64. doi:10.1029/2005RG000169.

[52] Journel A, Deutsch C, Desbarats A. Power averaging for block effective permeability. Proc SPE Calif Reg Meet 1986. doi:10.2118/15128-MS.

[53] Vidstrand P. Comparison of upscaling methods to estimate hydraulic conductivity. Ground Water 2001;39:401-7. doi:10.1111/j.1745-6584.2001.tb02324.x.

[54] Phillips SP, Belitz K. Calibration of a Texture???Based Model of a Ground???Water Flow System, Western San Joaquin Valley, California. Groundwater 1991;29:702-15. doi:10.1111/j.1745-6584.1991.tb00562.x.

[55] Benson CH, Zhai H, Rashad SM. Statistical Sample Size for Construction of Soil Liners. J Geotech Eng 1994;120:1704-24. doi:10.1061/(ASCE)0733-9410(1994)120:10(1704).

[56] Freeze R, Cherry J. Groundwater (p. 604). New Jersey: PrenticeHall Inc Englewood cliffs; 1979.

[57] White CD, Horne RN. Computing Absolute Transmissibility in the Presence of Fine-Scale Heterogeneity. SPE Symp. Reserv. Simul., Society of Petroleum Engineers; 1987. doi:10.2118/16011-MS. 
[58] Azevedo AAB de, Pressinotti MMN, Massoli M. Sedimentological studies of the Botucatu and Pirambóia formations in the region of Santa Rita do Passa Quatro (In portuguese). Rev Do Inst Geológico 1981;2:31-8. doi:10.5935/0100-929X.19810003.

[59] Giacheti HL, Rohm SA, Nogueira JB, Cintra JCA. Geotechnical properties of the Cenozoic sediment (In protuguese). In: Albiero JH, Cintra JCA, editors. Soil from Inter. São Paulo, Sao Paulo: ABMS; 1993, p. 143-75.

[60] Rohm SA. Shear strength of a non-saturated lateritic sandy soil in the São Carlos region (In portuguese). University of Sao Paulo, 1992.

[61] Soil Survey Staff. Soil Taxonomy: A Basic System of Soil Classification for Making and Interpreting Soil Surveys. Washington, D.C.: Blackwell Publishing Ltd; 1999. doi:10.1111/j.1475-2743.2001.tb00008.x.

[62] Santos HG dos, Jacomine PKT, Anjos LHC dos, Oliveira VÁ de, Lumbreras JF, Coelho MR, et al. Brazilian system of soil classification (In portuguese). 4th ed. Brasília, DF: EMBRAPA. Centro Nacional de Pesquisa de Solos; 2014.

[63] Matheron G. Principes of geostatistics. Econ. Geol., vol. 58, 1963, p. 1246-66. doi:10.2113/gsecongeo.58.8.1246.

[64] Remy N. SGeMS: Stanford Geostatistical Modeling Software. Softw Man 2004:1-87. doi:10.1007/978-1-4020-3610-1_89.

[65] Isaaks EH, Srivastava RM. An introduction to applied geostatistics. Oxford University Press; 1989.

[66] Vanmarcke E. Random Fields: Analysis and Synthesis. 1983.

[67] Griffiths D V., Fenton G a. Risk Assessment in Geotechnical Engineering. 2008.

[68] Gómez-Hernández JJ, Journel A. Joint Sequential Simulation of MultiGaussian Fields. Geostatistics Tróia '92, vol. 5, 1993, p. 85-94. doi:10.1007/978-94-011-1739-5_8. 
[69] Freeze R, Cherry J. Groundwater, 604 pp 1979.

[70] Lake LW. The Origins of Anisotropy (includes associated papers 18394 and 18458 ). J Pet Technol 1988;40:395-6. doi:10.2118/17652-PA.

[71] Diersch H-JG. Finite Element Modeling of Flow, Mass and Heat Transport in Porous and Fractured Media. 2014. doi:10.1007/978-3-642-38739-5.

[72] Giudici M, Vassena C. About the Symmetry of the Upscaled Equivalent Transmissivity Tensor. Math Geol 2007;39:399-408. doi:10.1007/s11004-007-9101-0.

[73] Tidwell VC, Wilson JL. Permeability Upscaling Measured on a Block of Berea Sandstone: Results and Interpretation. Math Geol 1999;31:749-69. doi:10.1023/A:1007568632217.

[74] Hunt AG. Scale-dependent hydraulic conductivity in anisotropic media from dimensional cross-over. Hydrogeol J 2006;14:499-507. doi:10.1007/s10040-005-0453-6.

[75] Tidwell VC. Scaling Issues in Porous and Fractured Media. Gas Transp. Porous Media, Springer Netherlands; 2006, p. 201-12. doi:10.1007/1-4020-3962-X_11.

[76] Selvadurai PA, Selvadurai APS. On the effective permeability of a heterogeneous porous medium: the role of the geometric mean. Philos Mag 2014;94:2318-38. doi:10.1080/14786435.2014.913111. 


\section{List of Tables}

Table 1 Block size used in the coarse models, total number of elements for the model and reduction factor of the number of elements when comparing to the fine-scale model.

Table 2 Statistics of qx computed form the model built at the fine-scale and for the models with all block side sizes studied 


\section{Table 1}

\begin{tabular}{lcccccccc}
\hline $\begin{array}{c}\text { Block side size } \\
(\mathbf{m})\end{array}$ & 0.2 & 0.4 & 0.5 & 0.8 & 1 & 2 & 4 & $12^{\mathrm{a}}$ \\
\hline $\begin{array}{c}\text { Total number of } \\
\text { elements }\end{array}$ & 48000 & 6000 & 3072 & 750 & 384 & 48 & 6 & 1 \\
\hline $\begin{array}{l}\text { Reduction factor } \\
\text { a: this value represents only the size at x-direction }\end{array}$ & & & & & & & & \\
\hline
\end{tabular}


Table 2

\begin{tabular}{|c|c|c|c|c|c|c|c|c|c|}
\hline \multicolumn{10}{|c|}{ Statistics of the $q_{x}$} \\
\hline & Fine & $0.2 \mathrm{~m}$ & $0.4 \mathrm{~m}$ & $0.5 \mathrm{~m}$ & $0.8 \mathrm{~m}$ & $1 \mathrm{~m}$ & $2 \mathrm{~m}$ & $4 \mathrm{~m}$ & $12 \mathrm{~m}$ \\
\hline $\begin{array}{l}\text { Mean } \\
{[\mathrm{m} / \mathrm{d}]}\end{array}$ & 0.92 & 0.92 & 0.92 & 0.92 & 0.92 & 0.93 & 0.93 & 0.93 & 1.09 \\
\hline $\begin{array}{l}\text { Std. Dev. } \\
\quad[\mathrm{m} / \mathrm{d}]\end{array}$ & 0.37 & 0.36 & 0.36 & 0.36 & 0.36 & 0.36 & 0.36 & 0.37 & 0.54 \\
\hline $\begin{array}{c}\text { Minimum } \\
\text { [m/d] }\end{array}$ & 0.35 & 0.34 & 0.34 & 0.34 & 0.34 & 0.34 & 0.34 & 0.35 & 0.37 \\
\hline $\begin{array}{c}\text { Maximum } \\
{[\mathbf{m} / \mathbf{d}]}\end{array}$ & 2.18 & 2.14 & 2.13 & 2.13 & 2.13 & 2.18 & 2.17 & 2.18 & 2.56 \\
\hline Coef. Var. & 0.40 & 0.39 & 0.39 & 0.39 & 0.39 & 0.38 & 0.38 & 0.40 & 0.50 \\
\hline
\end{tabular}




\section{List of Figures}

Fig. 1 Histograms and statistics of the measured $K(A)$ and $\ln K(B)$

Fig. 2. Isotropic experimental variogram and fitted model for the $\ln \mathrm{K}$ measured data

Fig. 3. Realizations numbers 1 (A) and 70 (B) of $\ln K$ at the fine-scale (color should be used)

Fig. 4 Upscaled lnK for realization number 1 for all block sizes (color should be used)

Fig. 5 Comparison of the specific discharge in the $\mathrm{x}$-direction (qx) through a plane orthogonal to the flow direction obtained from the model at the fine scale versus the results obtained from the models at coarser scales after computing the block values using the Laplacian-with-skin method Fig. 6 Variation of the mean and the standard deviation of the upscaled conductivities relative to the mean and standard deviation of the fine-scale conductivity values.

Fig. 7 Relative bias of head, RBh, for all block side sizes and all realizations when block values are computed with the Laplacian-with-skin upscaling method

Fig. 8 Cumulative frequency distribution function of qx at the fine-scale and qx values obtained for a homogeneous formation with conductivity equal to the harmonic, geometric and arithmetic means.

Fig. 9 Variation of the p-exponent with block side size

Fig. 10 Comparison of the specific discharge in the $\mathrm{x}$-direction (qx) obtained from the model performed at the fine-scale versus the results obtained from the models at coarser scales after computing the block values using p-norm average with the best p-exponent

Fig. 11 Relative bias of the piezometric head, RBh, for all block side sizes and all realizations when block values are computed using p-norm average with the best p-exponent

Fig. 12 Relative bias of the $\mathrm{qx}$ obtained with blocks computed using p-norm with $\mathrm{p}=-1$ (harmonic mean) 
Fig. 13 Relative bias of the $\mathrm{qx}$ obtained with blocks computed using p-norm with $\mathrm{p}=0$ (geometric mean)

Fig. 14 Relative bias of the qx obtained with blocks computed using p-norm with $\mathrm{p}=+1$ (arithmetic mean) 
Fig. 1
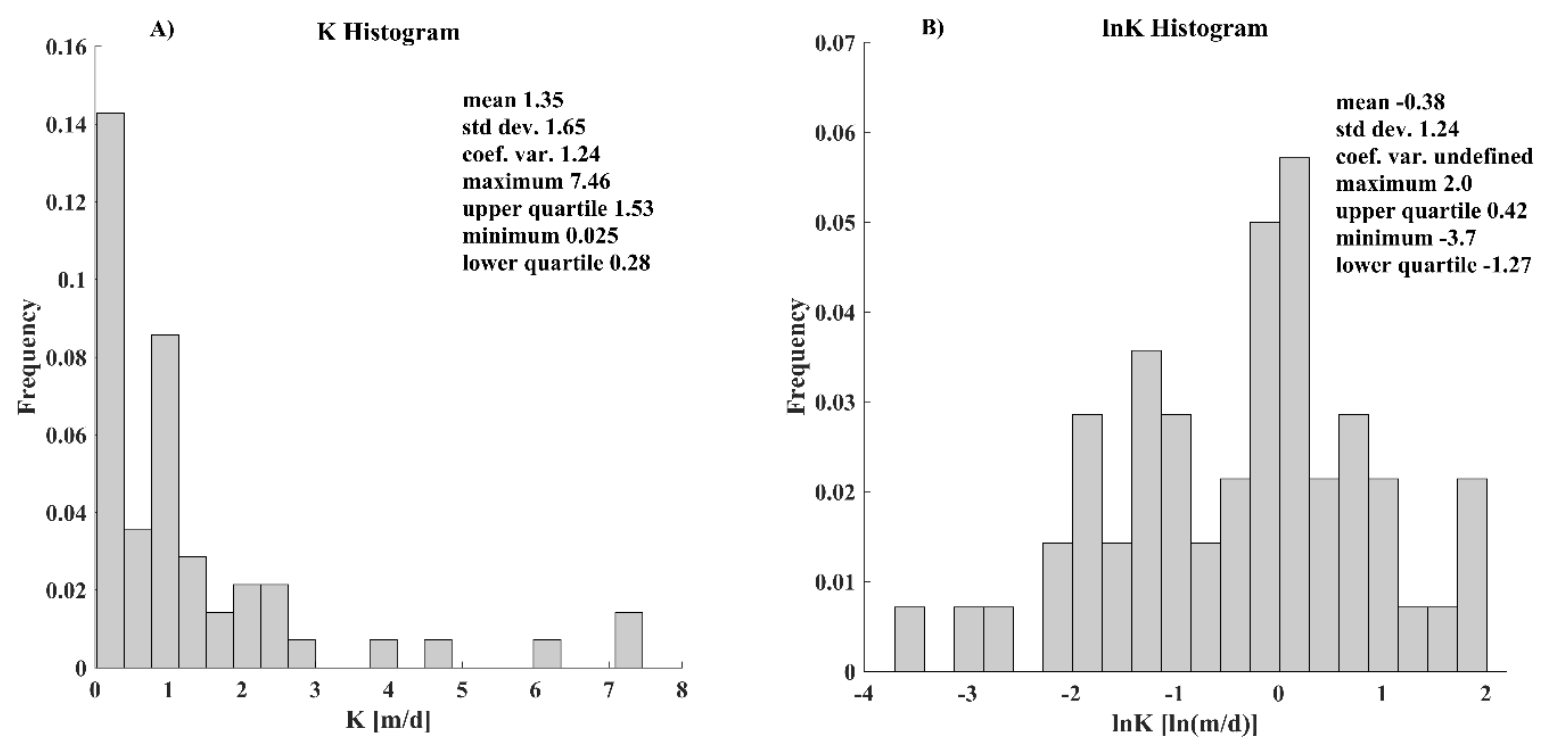
Fig. 2

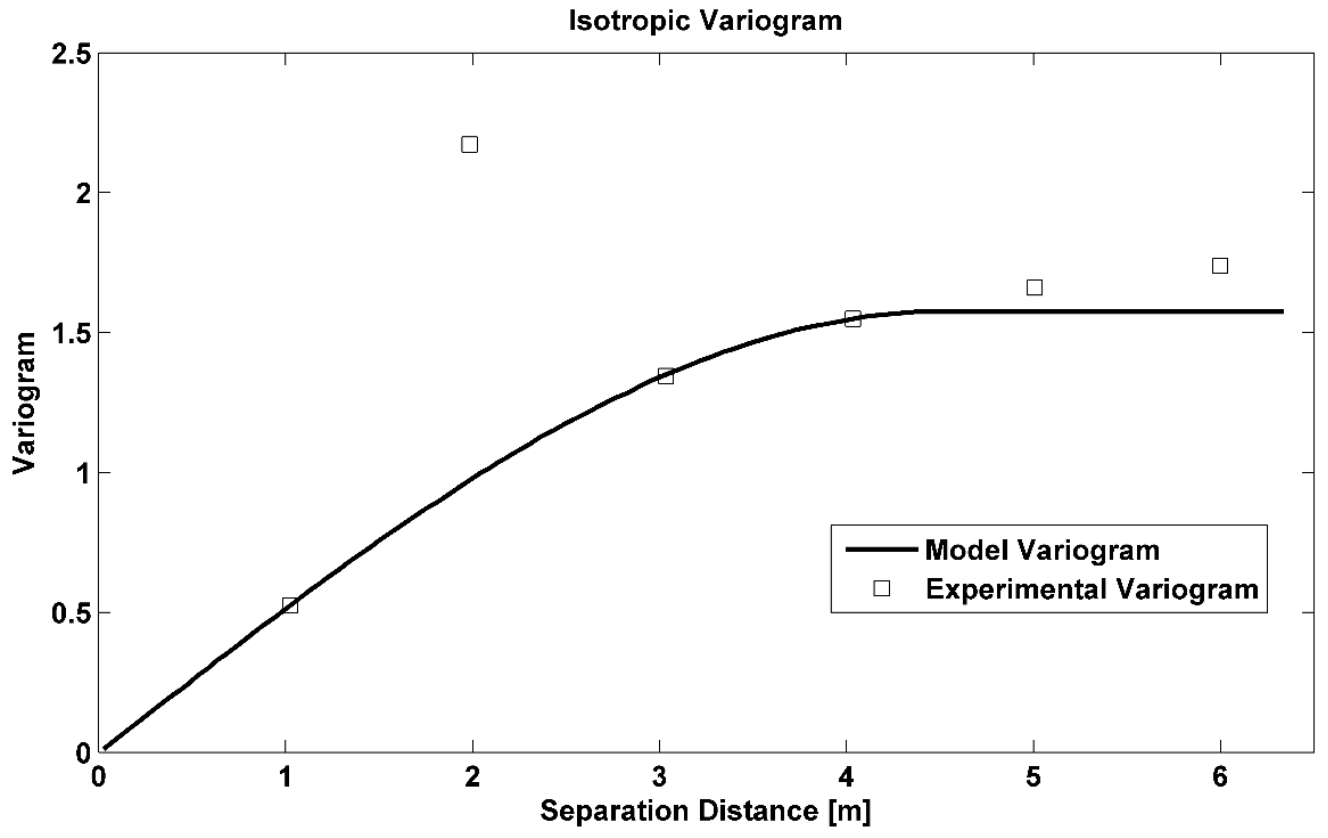


Fig. 3
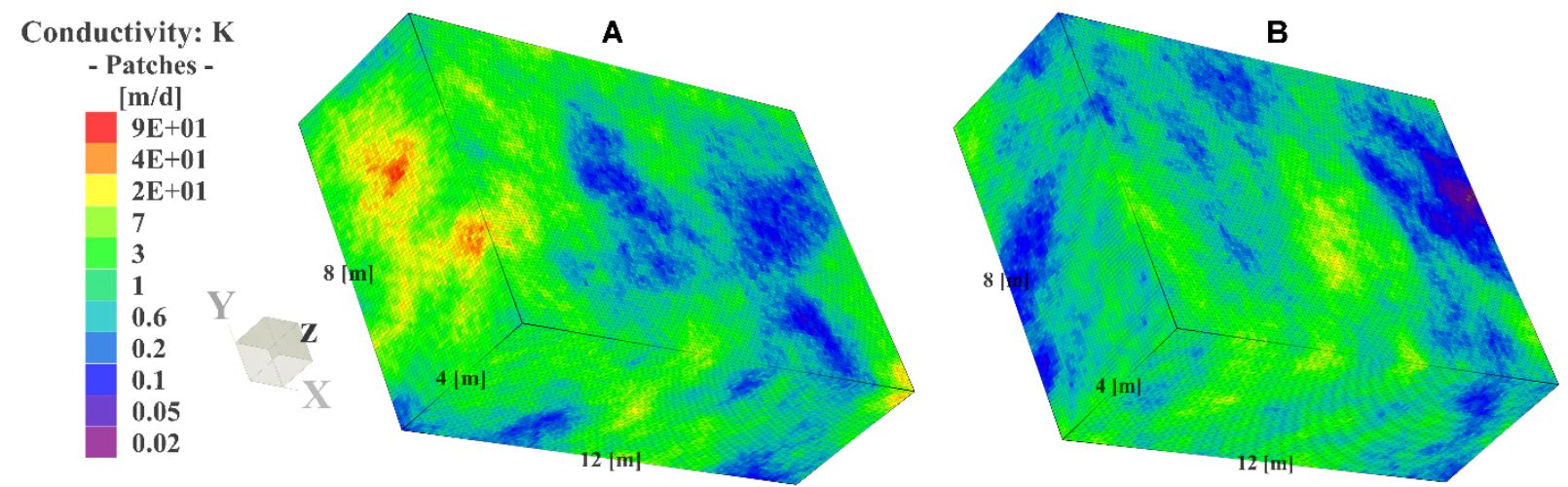
Fig. 4 

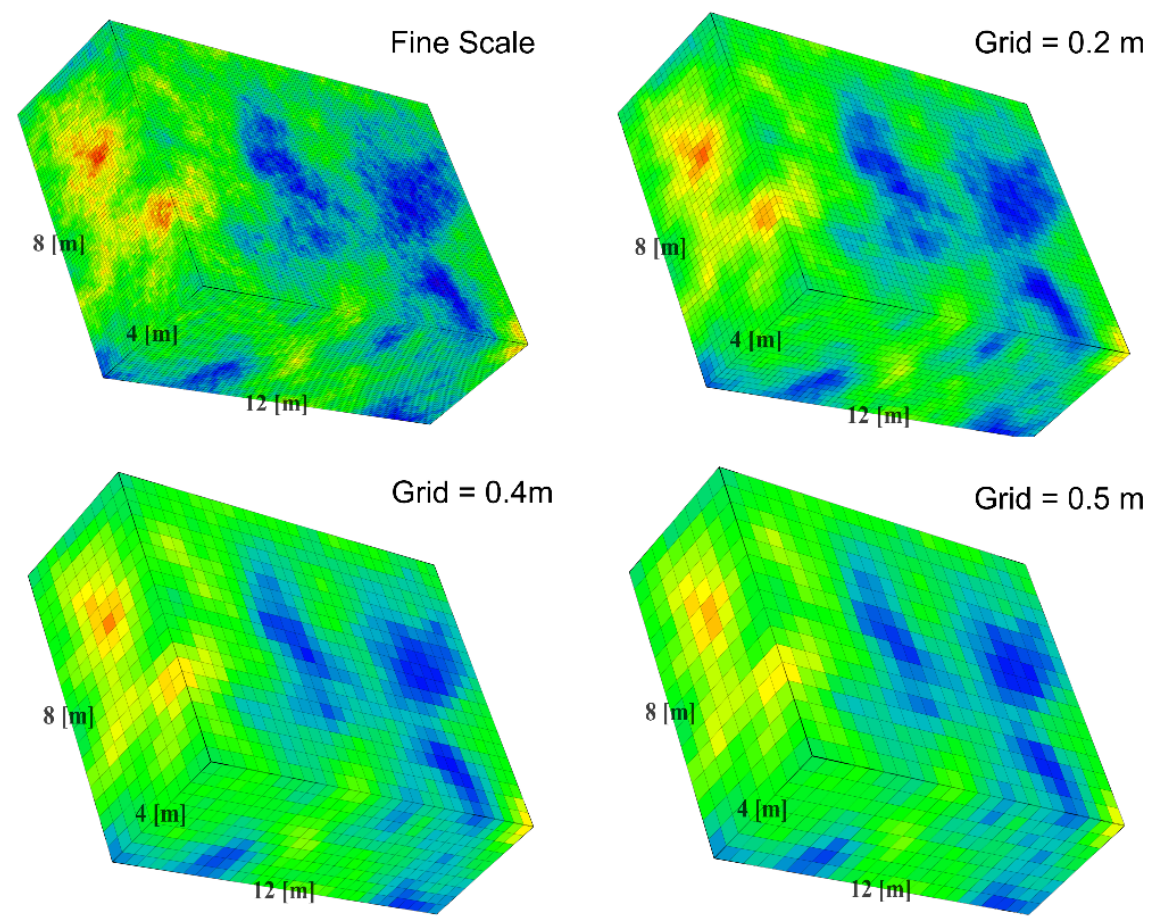

Conductivity: $\mathrm{K}$

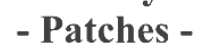
[m/d]

9E+01

$4 \mathrm{E}+01$

2E+01

7

3
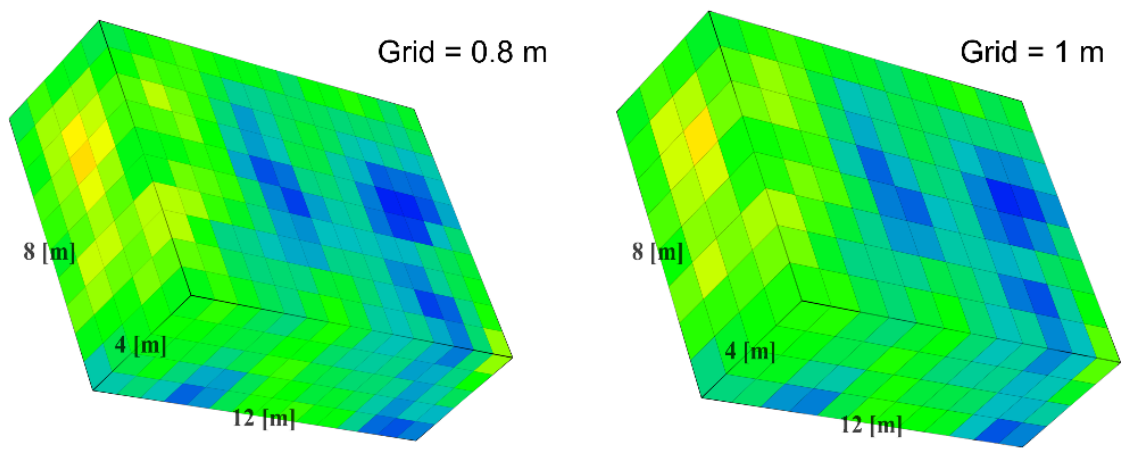

0.6

0.1

0.05

0.02
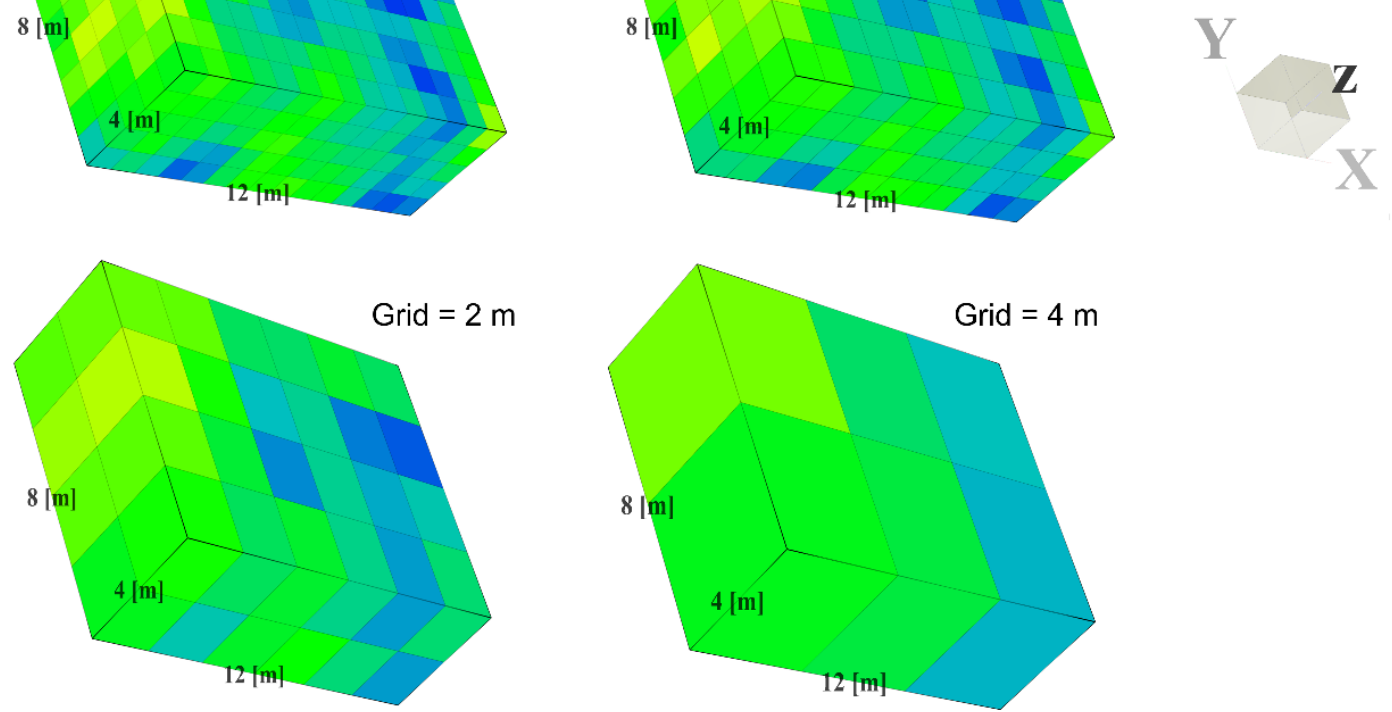
Fig. 5
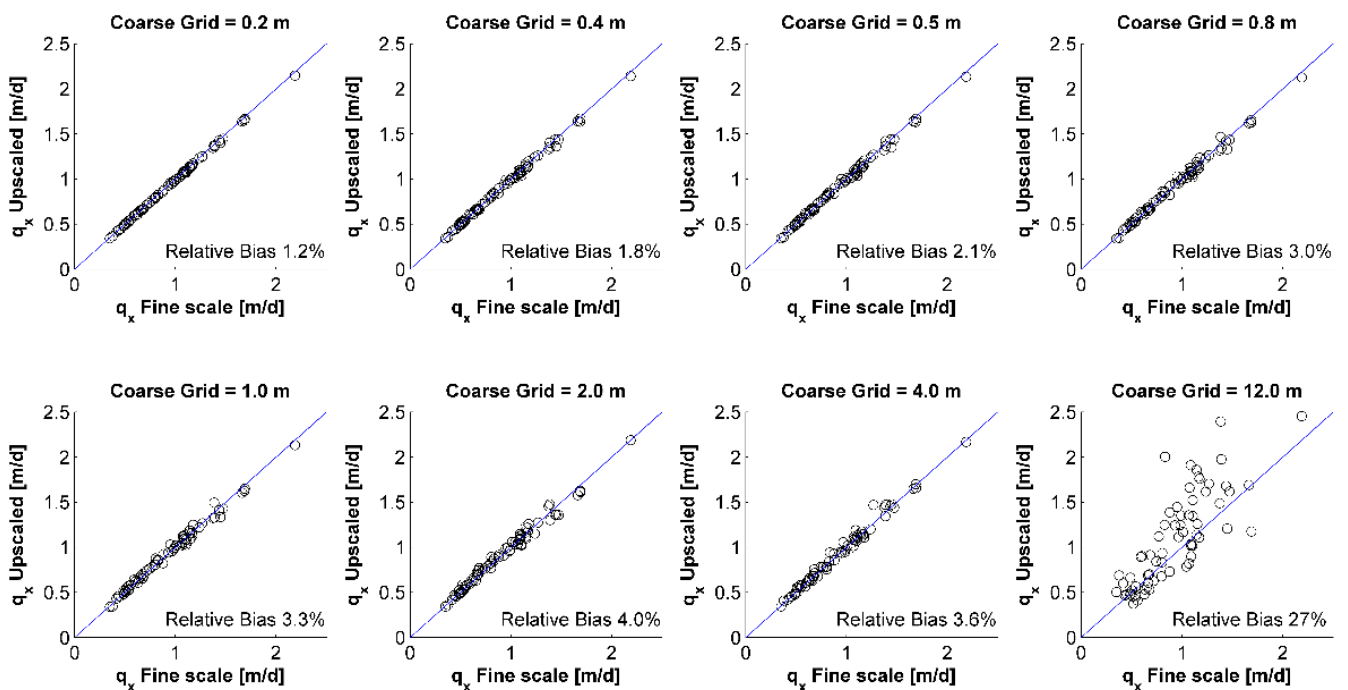
Fig.6
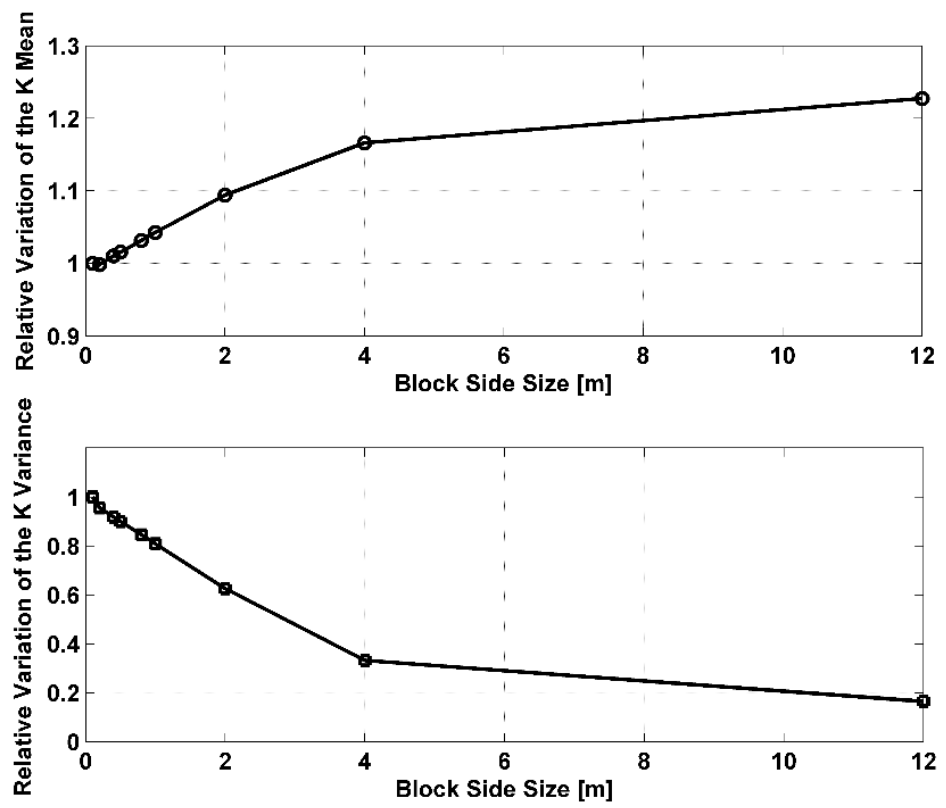
Fig. 7

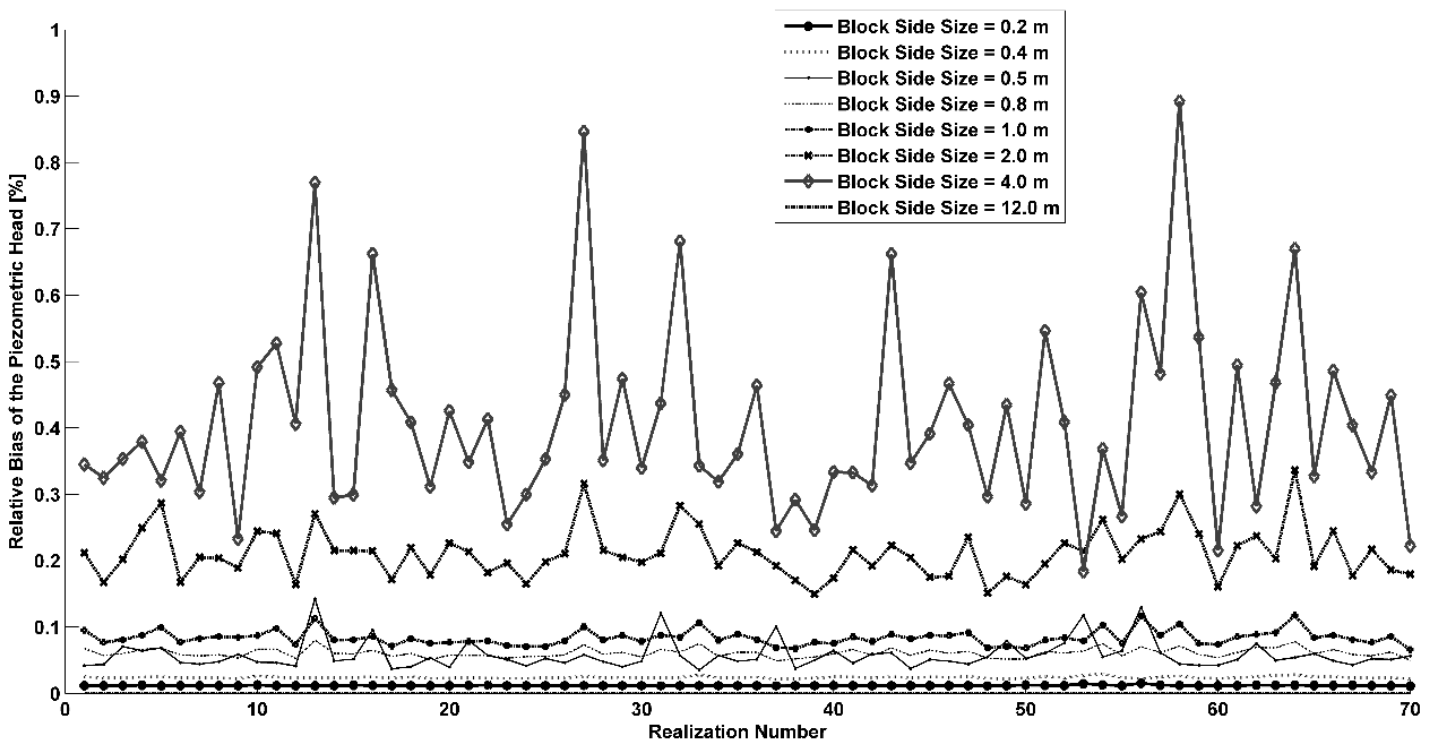


Fig.8

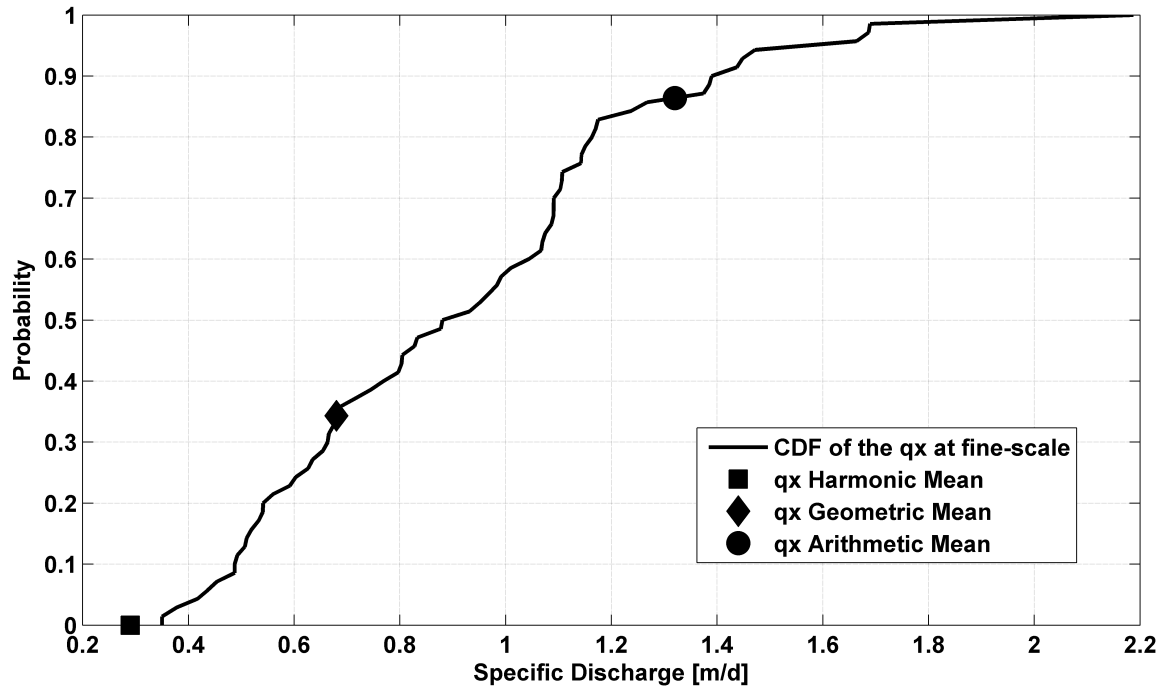


Fig.9

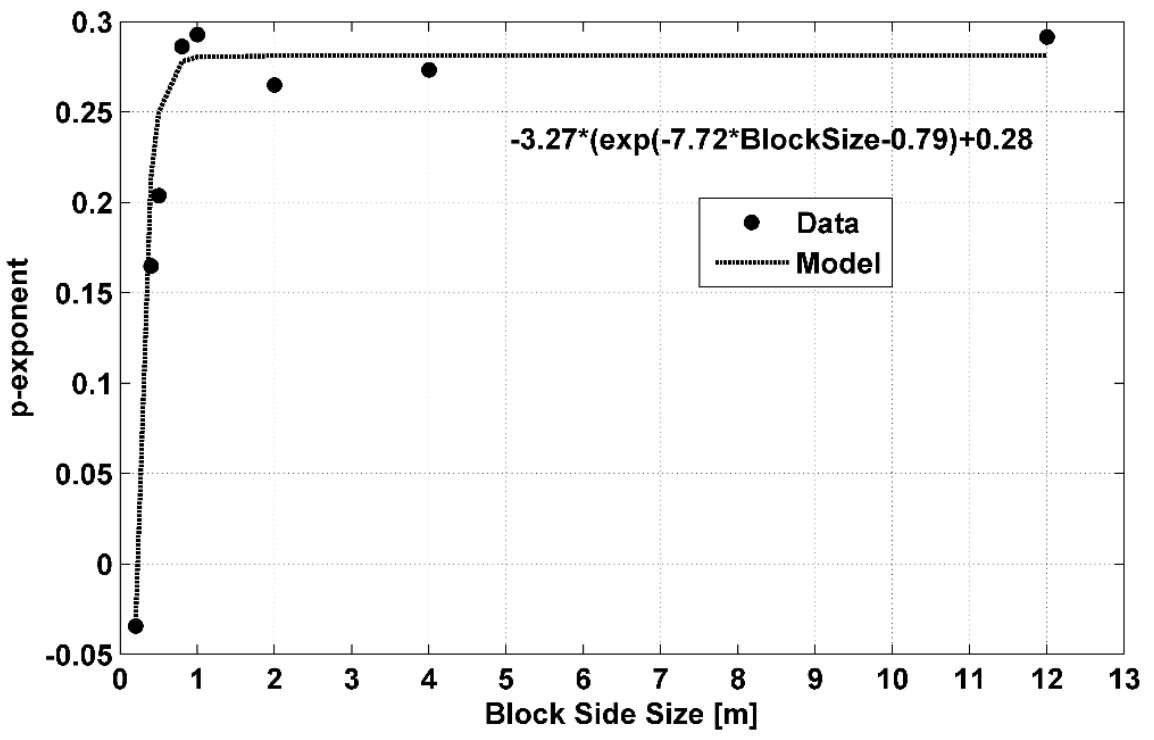


Fig. 10
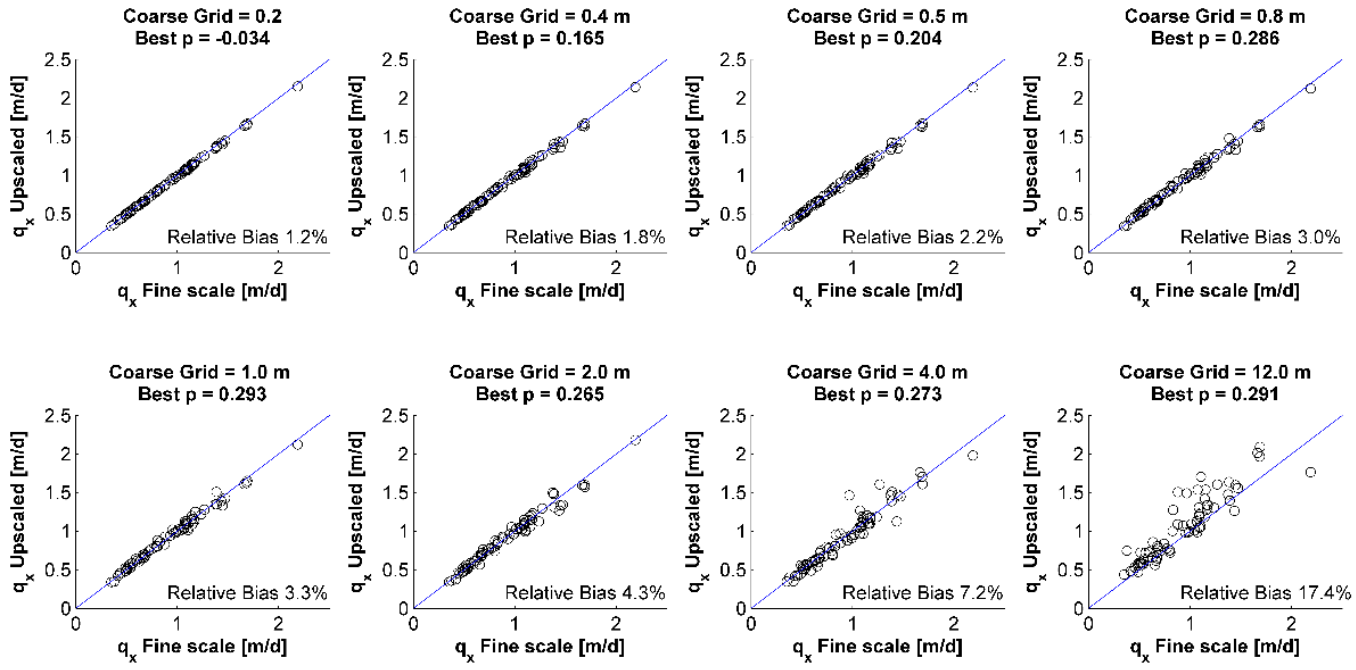
Fig. 11

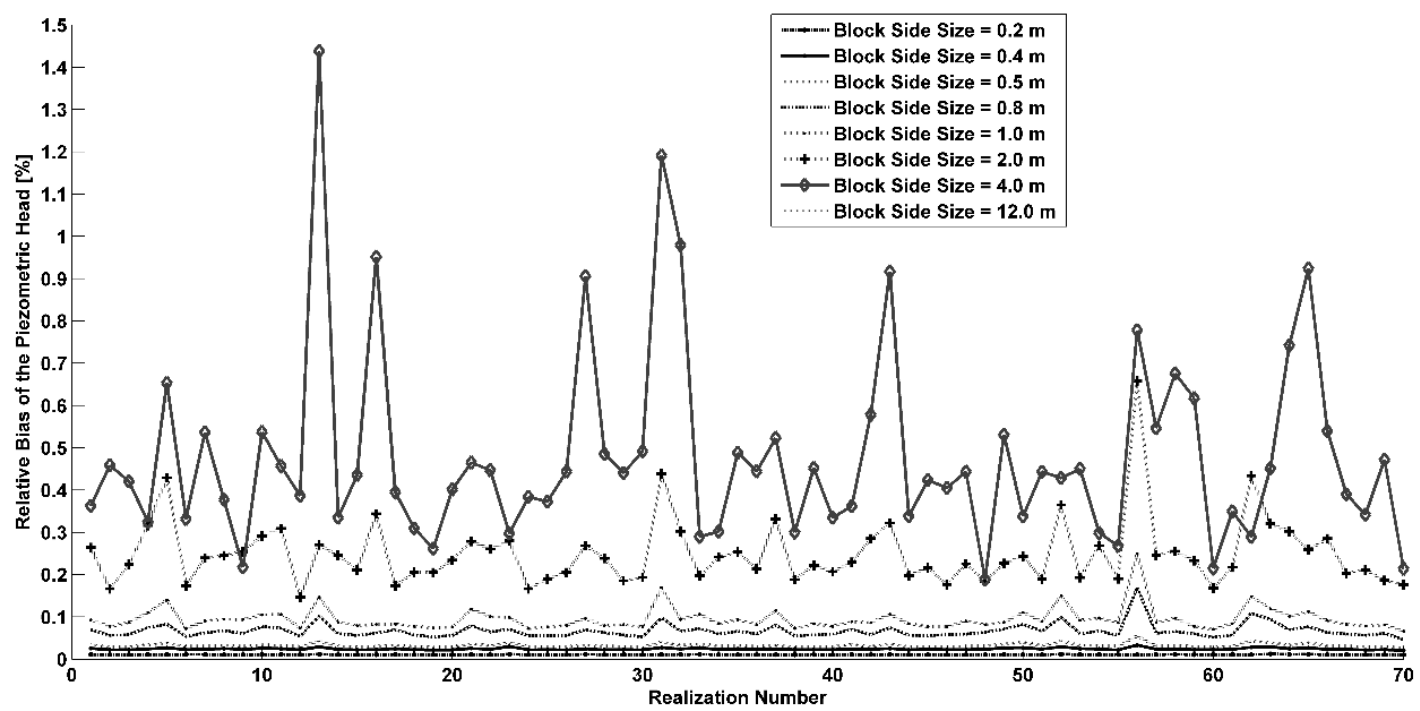


Fig. 12
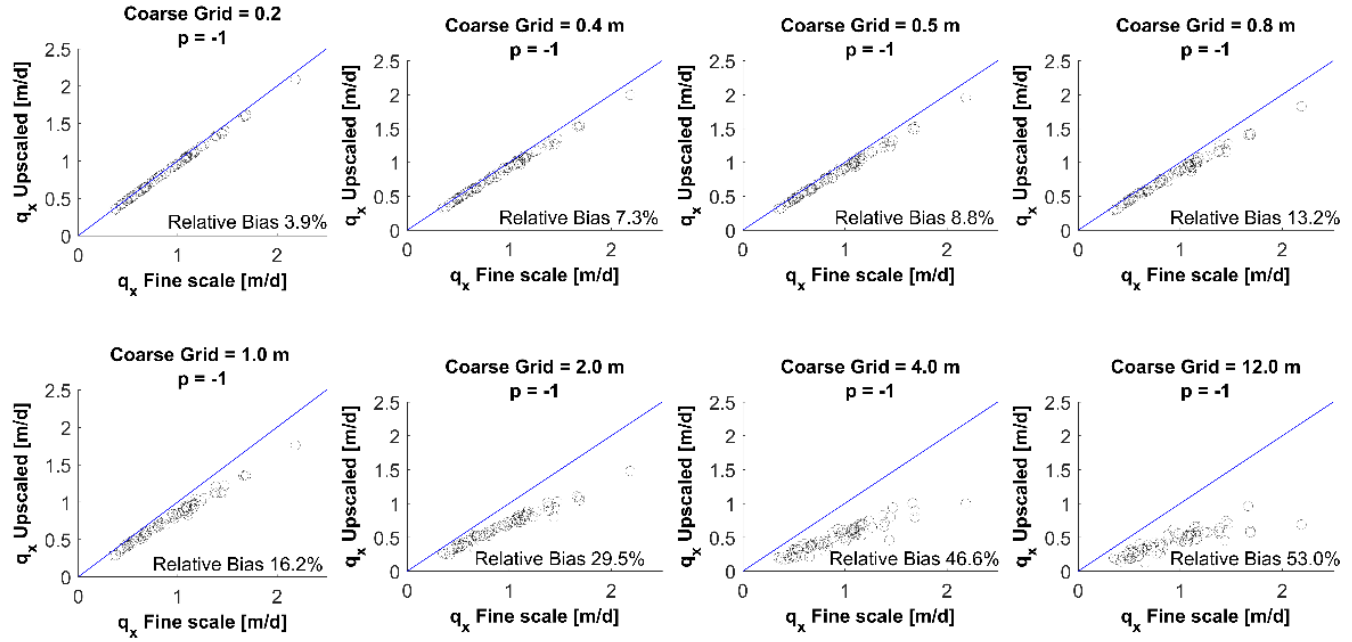
Fig 13
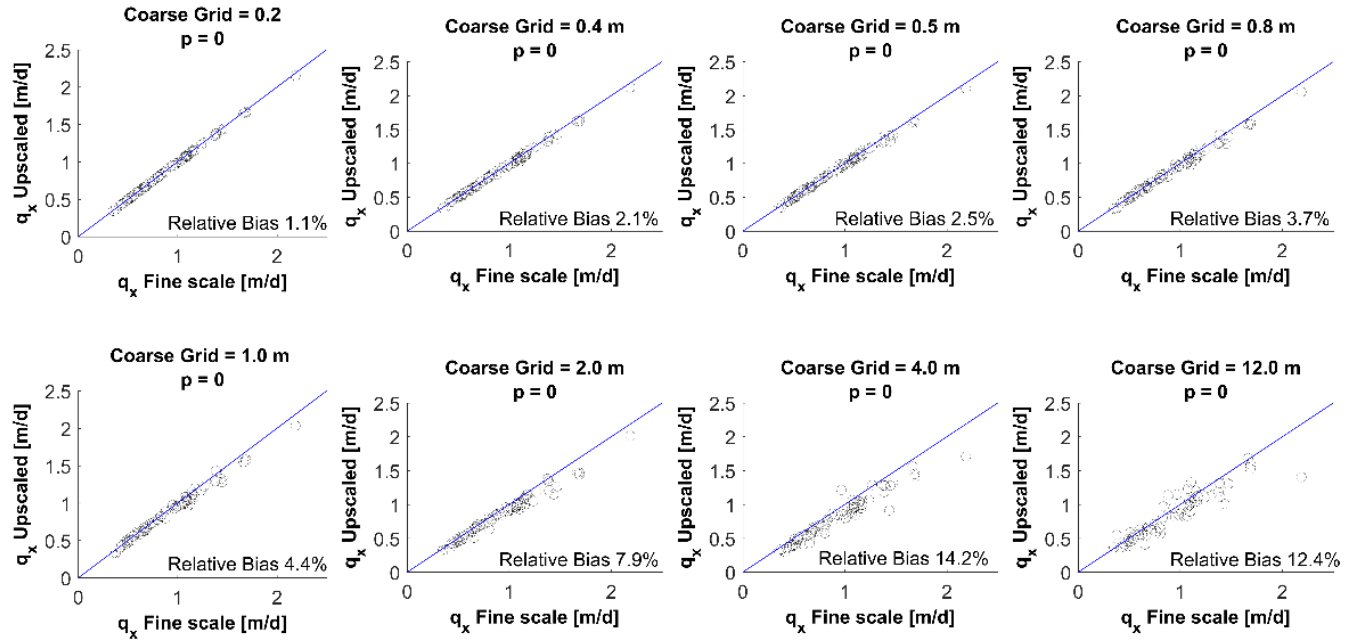
Fig 14
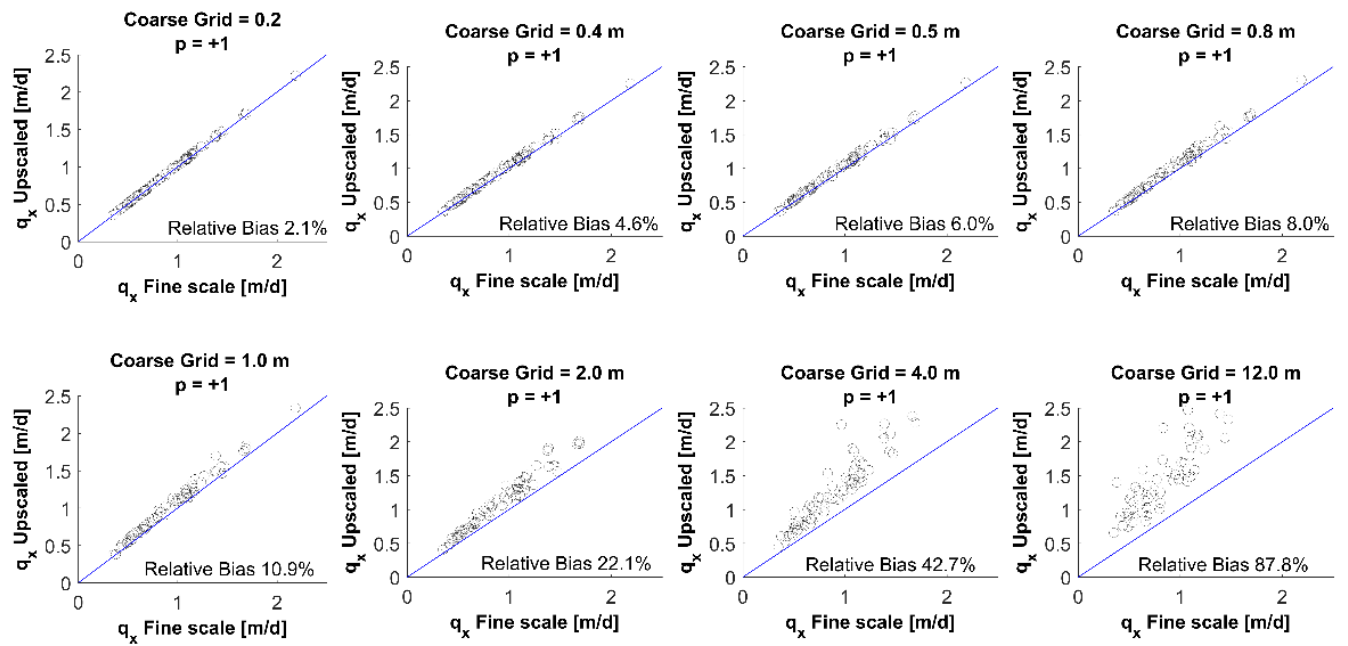